\title{
Dynamics and chemistry of tropospheric bromine explosion events in the Antarctic coastal region
}

\author{
U. Frieß, ${ }^{1,2}$ J. Hollwedel, ${ }^{1}$ G. König-Langlo, ${ }^{3}$ T. Wagner, ${ }^{1}$ and U. Platt $^{1}$ \\ Received 3 September 2003; revised 11 December 2003; accepted 13 January 2004; published 19 March 2004.
}

[1] We investigate chemistry and dynamics of bromine explosion events during Antarctic spring of 1999 and 2000 using ground-based differential optical absorption spectroscopy (DOAS) observations of $\mathrm{BrO}$, surface ozone, and ozone sounding measurements performed at the German research station Neumayer, located at the coast of the Antarctic continent $\left(70^{\circ} 39^{\prime} \mathrm{S}, 8^{\circ} 15^{\prime} \mathrm{W}\right)$. BrO maps from the GOME satellite instrument show huge areas of elevated $\mathrm{BrO}$ above the sea ice around Antarctica, covering several thousand square kilometers. Although the Neumayer station is located at a distance of only $7 \mathrm{~km}$ to the coast, bromine-activated air masses are only detected by our ground-based DOAS instrument under particular meteorological conditions. We use trajectory calculations in high temporal and spatial resolution in combination with sea ice maps to determine the source of air masses arriving at Neumayer. A comparison of these model calculations with measurements is in very good agreement with the theory that reactive bromine is heterogeneously released by sea-salt surfaces: in the majority of cases, enhanced levels of $\mathrm{BrO}$ are observed whenever a part of the probed air masses was previously in contact with sea ice surfaces, while depletion of surface ozone occurs only if the air at ground comes from the ice covered ocean. After being uplifted by advection processes, bromineactivated and ozone-depleted air masses are sometimes observed at high altitudes $(>4000 \mathrm{~m})$. This vertical transport of reactive bromine may have an impact on the free tropospheric ozone budget and on local climate in the Antarctic coastal region during springtime. $\mathrm{BrO}$ enhancements are usually accompanied by strong increases in light path (as detected by $\mathrm{O}_{4}$ ) owing to multiple scattering on aerosols, supporting the assumption that sea-salt particles, on which $\mathrm{BrO}$ recycling can take place, are present at the observation site. INDEX TERMS: 0322 Atmospheric Composition and Structure: Constituent sources and sinks; 0365 Atmospheric Composition and Structure: Troposphere-composition and chemistry; 0368 Atmospheric Composition and Structure: Troposphere - constituent transport and chemistry; KEYWORDS: $\mathrm{BrO}$, halogens, Antarctica, boundary layer, ozone, polar, DOAS

Citation: Frieß, U., J. Hollwedel, G. König-Langlo, T. Wagner, and U. Platt (2004), Dynamics and chemistry of tropospheric bromine explosion events in the Antarctic coastal region, J. Geophys. Res., 109, D06305, doi:10.1029/2003JD004133.

\section{Introduction}

[2] Sudden increases by orders of magnitude in boundary layer $\mathrm{BrO}$ concentrations during spring has been found both in the Arctic [Hausmann and Platt, 1994; Tuckermann et al., 1997; Hönninger and Platt, 2001] and in the Antarctic [Kreher et al., 1997]. Simultaneous to elevated levels of $\mathrm{BrO}$, enhanced concentrations of water soluble bromine species in sea-salt aerosols that can be collected by aerosol filters have been found [Langendörfer et al., 1990]. Huge

\footnotetext{
${ }^{1}$ Institut für Umweltphysik, University of Heidelberg, Heidelberg, Germany.

${ }^{2}$ Now at Space Research Centre, University of Leicester, Leicester, UK.

${ }^{3}$ Alfred Wegener Institut für Polar- und Meeresforschung, Bremerhaven, Germany.

Copyright 2004 by the American Geophysical Union. 0148-0227/04/2003JD004133\$09.00
}

"clouds" of $\mathrm{BrO}$ enriched air masses have been observed from satellite measurements, covering areas of several thousand $\mathrm{km} 2$ over the polar sea ice of both hemispheres [Wagner and Platt, 1998; Richter et al., 1998; Hegels et al., 1998]. These events of highly elevated $\mathrm{BrO}$ in polar regions, with mixing ratios of up to $30 \mathrm{ppt}$, have been always coincident with low levels of ozone in the marine boundary layer (MBL), strongly suggesting that reactive bromine is responsible for its catalytic destruction. Enhanced $\mathrm{BrO}$ in the boundary layer associated with ozone destruction has also been detected over the Caspian Sea [Wagner and Platt, 1998] and in the Dead Sea basin [Hebestreit et al., 1999].

[3] A mechanism suggested to cause the observed sudden $\mathrm{BrO}$ enhancements in the MBL is the autocatalytic release of $\mathrm{BrO}$ involving heterogeneous reactions on sea-salt surfaces [Fan and Jacob, 1992; Tang and McConnel, 1996; Vogt et al., 1996]. The release of reactive halogens from acidic sea-salt surfaces occurs via the uptake of $\mathrm{HOBr}$ 
formed in the gas phase by the following (simplified) sequence of reactions:

$$
\begin{gathered}
\mathrm{Br}+\mathrm{O}_{3} \rightarrow \mathrm{BrO}+\mathrm{O}_{2} \\
\mathrm{BrO}+\mathrm{HO}_{2} \rightarrow \mathrm{HOBr}+\mathrm{O}_{2} \\
\mathrm{HOBr}+\mathrm{Br}_{a q}^{-}+\mathrm{H}_{a q}^{+} \rightarrow \mathrm{Br}_{2}+\mathrm{H}_{2} \mathrm{O}_{a q} \\
\mathrm{Br}_{2}+h \nu \rightarrow 2 \mathrm{Br} .
\end{gathered}
$$

[4] Here (aq) denotes the aqueous phase, i.e., reactions on sea-salt surfaces. In summary, the oxidation of $\mathrm{Br}^{-}$to $\mathrm{Br}$ by $\mathrm{O}_{3}$ leads to the release of up to two halogen atoms for each halogen atom scavenged by the sea-salt surface as $\mathrm{HOBr}$. Under particular circumstances this mechanism can lead to an exponential growth of gaseous reactive bromine, the bromine explosion [Platt and Lehrer, 1997].

[5] The above described bromine release from sea salt only occurs for $\mathrm{pH}<6.5$ [Fickert et al., 1999]. A high acidity of the aerosol could by caused by the uptake of strong acids, such as $\mathrm{HNO}_{3}$ and $\mathrm{H}_{2} \mathrm{SO}_{4}$ [Lehrer, 1999]. Obviously, an exponential increase in gaseous reactive halogen compounds can only take place if more than one halogen atom is produced for each scavenged hypohalogenic acid molecule in reaction cycles (2)-(4). Therefore analogous "iodine" and "chlorine explosion" mechanisms are unlikely to exist: the gas-phase conversion of $\mathrm{Cl}$ to $\mathrm{HOCl}$ is too inefficient, and the concentration of particulate iodine is too small [Gäbler and Heumann, 1993].

[6] Frost flowers, which are formed on a liquid layer with high salinity on top of the sea ice surface, are likely to provide a large surface area for heterogeneous reactions and thus could be a major source for reactive bromine [Rankin et $a l ., 2002]$. Uptake of these fragile crystals by wind may lead to their transport to the inland. Prerequisites for bromine explosions are meteorological conditions that prevent boundary layer air from mixing with air from the free troposphere, keeping the concentrations of the bromine reactants close to the surface high. Caused by the negative radiation budget of the surface and the subsequent cooling of the atmosphere at the ground, strong inversion layers are formed in the lowermost few $100-1000 \mathrm{~m}$ of the polar atmosphere during late winter and spring, which are of importance for bromine explosions since they effectively confine surface emissions to the boundary layer.

[7] A further prerequisite for the autocatalytic bromine release and the subsequent destruction of ozone is the availability of sunlight (reaction (4)), which is provided after polar sunrise. Because of these prerequisites (strong surface inversions, sunlight), episodes of bromine explosion events and boundary layer ozone depletion in polar regions are only observed during spring.

[8] Reactive bromine compounds in the troposphere can destroy ozone by catalytic reaction cycles, involving either the $\mathrm{BrO} / \mathrm{BrO}$ self reaction (I):

$$
\begin{aligned}
& 2\left(\mathrm{Br}+\mathrm{O}_{3} \rightarrow \mathrm{BrO}+\mathrm{O}_{2}\right) \\
& \mathrm{BrO}+\mathrm{BrO} \rightarrow \mathrm{Br}_{2}+\mathrm{O}_{2} \\
& \mathrm{Br}_{2}+\mathrm{h} \nu \rightarrow 2 \mathrm{Br} \quad \lambda<600 \mathrm{~nm} \\
& \text { net }: \quad 2 \mathrm{O}_{3}+h \nu \rightarrow 3 \mathrm{O}_{2}
\end{aligned}
$$

or the reaction of $\mathrm{BrO}$ with $\mathrm{HO}_{2}$ (II):

$$
\begin{gathered}
\mathrm{Br}+\mathrm{O}_{3} \rightarrow \mathrm{BrO}+\mathrm{O}_{2} \\
\mathrm{OH}+\mathrm{O}_{3} \rightarrow \mathrm{HO}_{2}+\mathrm{O}_{2} \\
\mathrm{BrO}+\mathrm{HO}_{2} \rightarrow \mathrm{HOBr}+\mathrm{O}_{2} \\
\mathrm{HOBr}+h \nu \rightarrow \mathrm{OH}+\mathrm{Br} \\
\text { net }: \quad 2 \mathrm{O}_{3}+h \nu \rightarrow 3 \mathrm{O}_{2} .
\end{gathered}
$$

[9] In addition, there might be some contribution from $\mathrm{BrO}+\mathrm{ClO}$ and $\mathrm{BrO}+\mathrm{IO}$ reactions [Frieß $\beta$ et al., 2001]. These cycles can lead to the complete destruction of boundary layer ozone during bromine explosion events, referred to as the "tropospheric ozone hole." Note that cycle (I) is of second order in $\mathrm{BrO}$, while cycle (II) is of first order in BrO. Therefore cycle (I) will dominate at high $\mathrm{BrO}$ levels, cycle (II) at low levels.

[10] Here we present springtime measurements of $\mathrm{BrO}$ in the Antarctic coastal region during 1999 and 2000. Slant columns of $\mathrm{BrO}$ are detected by observing zenith scattered sunlight by DOAS [Platt, 1994]. Our DOAS spectrograph is operated at the trace gas observatory of the German Antarctic research station Neumayer $\left(70^{\circ} 39^{\prime} \mathrm{S}, 8^{\circ} 15^{\prime} \mathrm{W}\right)$, located on the shelf ice in front of the Antarctic continent at a distance of approximately $7 \mathrm{~km}$ from the sea. The DOAS instrument and the spectral analysis of $\mathrm{BrO}$ are described in section 2.1. Since clouds and/or snow drift can have a strong impact on the tropospheric BrO slant column density (SCD), we discuss in section 2.2 how the absorption of the oxygen dimer $\left(\left(\mathrm{O}_{2}\right)_{2}\right)$ can be used to characterize nearsurface multiple scattering of radiation. To investigate the influence of boundary layer $\mathrm{BrO}$ on tropospheric ozone, we use data from an in situ ozone monitor operating at Neumayer station and ozone concentration profiles observed by regularly launched ozone soundings. The instrumentation for in situ ozone measurements is described in section 2.3. The source regions of $\mathrm{BrO}$ containing air masses and the vertical distribution of $\mathrm{BrO}$ in the lower troposphere is investigated using satellite observations of the sea ice coverage in the south polar sea in combination with trajectory calculations in high temporal and spatial resolution. These model calculations are described in section 2.4. Finally, we compare our ground-based data with $\mathrm{BrO}$ maps from the GOME satellite instrument, which is briefly summarized in section 2.5 .

\section{Instruments and Data Analysis}

\subsection{DOAS Observations of $\mathrm{BrO}$}

[11] The DOAS instrument operating at Neumayer station is based on a spectrograph system originally developed for balloonborne measurements [Ferlemann et al., 2000; Frie $\beta$ et al., 2001]. It consists of two small telescopes acting as entrance optics, a dual channel spectrograph/detector unit for the UV and visible wavelength region, and a quartz fiber 
bundle which conducts the light from the entrance optics to the spectrograph.

[12] The entrance optics are located inside a stainless steel housing mounted on the roof of the trace gas observatory. Zenith scattered sunlight enters through a $45^{\circ}$ slanted quartz glass window and is focused on the entrances of two fiber bundles by two quartz glass lenses with $f=50 \mathrm{~mm}$ focal length.

[13] This optical setup leads to an instrument's field of view of less than $1^{\circ}$. Electrical heaters $(100 \mathrm{~W})$ prevent ice and water condensation and freezing on the optical parts inside the telescope housing. The telescope is equipped with a halogen and a mercury lamp. Their light can be focused on the fiber entrance of each spectrograph without using any mechanical parts, such as movable mirrors, which could easily fail in the cold and stormy environment. For this purpose the light emitted by either lamp is split into two beams, one for each telescope, using a beam splitter cube. A mirror system projects the light to the inner surface of the entrance window where it is partially reflected into the telescopes. Therefore, in addition to background spectra (offset and dark current), reference spectra of the mercury and halogen lamps can be recorded automatically each night. During summer, when there is permanent daylight, these measurements are performed manually once per week after covering the entrance window of the telescopes to prevent ambient light from entering the instrument. These regularly performed calibration measurements allow us to characterize the long term stability of the instrument.

[14] Light collected by the telescope is conducted to the spectrograph unit by two quartz fiber bundles consisting of 14 individual fibers with $120 \mu \mathrm{m}$ diameter each. At the fiber bundles exit the 14 quartz fibers are arranged as columns, serving as entrance slits entrance slit for two separate spectrograph/detector units for the UV and visible (Vis) wavelength range, located in a single aluminum housing. Aluminum was chosen to avoid temperature gradients and to ensure a good thermal stability of the instrument. The optical parts of the spectrograph are mounted in a "sandwich" design between 3 and $5 \mathrm{~mm}$ thick stainless steel plates which ensure a high mechanical stability. All inner parts are blackened using Teflon coating to reduce instrumental stray light. The housing is evacuated $\left(\mathrm{p}<10^{-5} \mathrm{mBar}\right)$ and filled with dry argon under slight overpressure to avoid any freezing or condensation of water onto the cooled detector surfaces. The light is dispersed in each spectrograph using concave holographic gratings and then detected using photodiode arrays (PDAs) (Hamamatsu ST3904-1024). The UV grating (Yobin Yvon, $1200 \mathrm{gr} / \mathrm{mm}$ ) has a focal length of $210 \mathrm{~mm}(\mathrm{f} / 3.2)$ and is operated in the $-1 \mathrm{st}$ order. The average spectral resolution of the UV spectrograph is $0.5 \mathrm{~nm}$ (5.0 channels). The PDAs consist of 1024 individual Si CMOS photodiodes of $2.5 \mathrm{~mm}$ height and $25 \mu \mathrm{m}$ width. The detectors are cooled to $238 \mathrm{~K}$ using two-stage thermoelectric peltier cascades, leading to an average dark current signal of 0.2 digital units per second. To protect the sensitive detector surface, photodiode arrays are often equipped with a quartz window. This can lead to Fabry-Perot etalon structures caused by interference effects on the glass surfaces. If these structures vary with time owing to condensation of water vapor, they can strongly affect the spectral retrieval. To avoid these problems, the PDAs are operated without quartz glass windows.

[15] To minimize changes in the optical adjustments and to improve the detector cooling, the housing is held at a stable temperature of $263 \mathrm{~K}$ using a commercial water cooling device with a heat exchanger mounted on top of the spectrograph housing. The water cooling simultaneously removes the heat of the Peltier elements. The whole instrument is located inside a box with $80 \mathrm{~mm}$ thick styrofoam insulation. Depending on light conditions, spectra are sampled each 3-5 min whenever the solar zenith angle (SZA) is $<97^{\circ}$.

[16] The spectral retrieval relies on the DOAS method, which is based on the well-known Lambert-Beer law:

$$
I(\lambda)=I_{0}(\lambda) \cdot \exp \left(-\sum_{j} \int_{0}^{L} \rho_{j}(s) \cdot \sigma_{j}(\lambda, T(s), p(s)) d s\right) .
$$

[17] Equation (12) describes the relationship between the incident $\left(I_{0}(\lambda)\right)$ and transmitted $(I(\lambda))$ light intensity as a function of wavelength $\lambda$ when passing a mixture of $j$ absorbers with concentrations $\rho_{j}$ and temperature and pressure dependent absorption cross sections $\sigma_{j}(\lambda, T, p)$. The integration in equation (12) is performed along the light path with length $L$. The slant column density (SCD) of species $j, S_{j}$ is defined as the integrated concentration of the $j$ th absorber along the light path:

$$
S_{j}=\int_{0}^{L} \rho_{j}(s) d s
$$

[18] When neglecting the temperature and pressure dependence of the absorption cross sections, the SCDs $S_{j}$ can be determined by applying a nonlinear least squares fit to equation (12):

$$
\begin{aligned}
\chi^{2}= & \frac{1}{N} \cdot \sum_{k=1}^{N}\left(\ln \left(I\left(\lambda_{k}+s_{0}+\lambda_{k} \cdot s_{1}\right)\right)-\ln \left(I_{0}\left(\lambda_{k}\right)\right)+\sum_{j} \sigma_{j}\left(\lambda_{k}\right) S_{j}\right. \\
& \left.+\sum_{n} c_{n} \lambda_{k}^{n}\right)^{2} \stackrel{!}{\longrightarrow} \min .
\end{aligned}
$$

[19] The summation is performed over a discrete wavelength interval, where $\lambda_{k}$ is the center wavelength recorded by the $k$ th photodiode in the spectrometer's focal plane. The polynomial $\sum_{n} c_{n} \lambda_{k}^{n}$ accounts for the broadband spectral structure caused by atmospheric Rayleigh and Mie scattering. The nonlinear fit parameters $s_{0}$ and $s_{1}$ describe a wavelength shift and squeeze, respectively, which accounts for possible changes in the spectral alignment of the instrument [Stutz and Platt, 1996]. The quantity $\chi$ is referred to as the root mean squares (RMS) deviation of the spectral analysis. Here $\chi^{2}$ is minimized using the single value decomposition method [Press et al., 1988] in combination with the Levenberg- Marquardt algorithm [Levenberg, 1944; Marquardt, 1963]. In practice, a spectrum recorded at low SZA $\Theta$ and thus small trace gas absorption is chosen as the reference spectrum $I_{0}$. Thus solving equation (14) yields the so-called differential slant column density (dSCD), defined as

$$
\Delta S(\Theta)=S(\Theta)-S_{\text {ref }}
$$


where $S_{\text {ref }}$ and $S(\Theta)$ are the slant column densities of the socalled Fraunhofer reference spectrum $I_{0}$ and the atmospheric spectrum $I$, respectively.

[20] According to the recommendations of Aliwell et al. [2002], the $\mathrm{BrO}$ retrieval is performed in the wavelength interval between 346 and $358.5 \mathrm{~nm}$ (124 pixels) using the WINDOAS spectral retrieval software (C. Fayt and M. van Roozendael, IASB Brussels, personal communication, 1999). This wavelength region encompasses two vibrational absorption bands of $\mathrm{BrO}$. The absorption of $\mathrm{BrO}$, ozone, $\mathrm{NO}_{2}, \mathrm{O}_{4}$, and $\mathrm{OClO}$ are accounted for by fitting cross sections taken from the literature as listed in Table 1. All cross sections are convoluted to the instrument's resolution using an instrument function determined by recording the shape of the mercury emission line at $334.15 \mathrm{~nm}$. The strong temperature dependence of the ozone absorption in this wavelength region is accounted for by simultaneously fitting three ozone cross sections recorded at 203, 246, and 280 K. A synthetic Ring spectrum [Solomon et al., 1987; Chance and Spurr, 1997] accounts for changes in the optical depth of the Fraunhofer lines owing to rotational Raman scattering (Ring effect) [Grainger and Ring, 1962]. A third degree polynomial is included in the fit to remove the broadband features caused by atmospheric Rayleigh and Mie scattering. Two different Fraunhofer reference spectra are used in the retrieval of the 1999 and 2000 measurements, respectively, both recorded in mid-October of the respective year (6 October 1999 and 16 October 2000, respectively). Using only a single Fraunhofer reference spectrum for each season produces a consistent data set, with only a constant offset owing to the unknown amount of $\mathrm{BrO}$ in the reference spectrum, while using a daily Fraunhofer reference spectrum would introduce unknown offsets which vary from day to day owing to varying values of $S_{\text {ref }}$. The spectral noise is reduced by applying a single triangular smoothing both to the spectra and to the cross sections prior to the spectral retrieval. While the Fraunhofer reference spectra and the cross sections are fixed in wavelength, the atmospheric spectra are allowed to shift and squeeze in order to compensate for possible small changes in the wavelength calibration of the instrument.

[21] An example of the spectral retrieval of $\mathrm{BrO}$ (together with $\mathrm{O}_{3}, \mathrm{O}_{4}, \mathrm{NO}_{2}$, and $\mathrm{OClO}$ ) for a spectrum recorded at $90^{\circ} \mathrm{SZA}$ on 20 September 2000 is shown in Figure 1. The RMS residual of the spectral retrieval during twilight ranges between $\chi=5 \times 10^{-4}$ during 2000 and $\chi=7 \times 10^{-4}$ during 1999 , corresponding to a $\mathrm{BrO}$ fit error of $(3.1-4.2) \times$ $10^{13}$ molecules $/ \mathrm{cm}^{2}(1 \sigma)$.

[22] According to the definition of the detection limit by Stutz and Platt [1996], the minimum detectable $\mathrm{BrO}$ column is $S_{\text {limit }} \approx 3.7 \times 10^{13}$ molecules $/ \mathrm{cm}^{2}$ (for an RMS residual of $\chi=5 \times 10^{-4}$ ), while typical stratospheric

Table 1. Cross Sections Used for the Spectral Retrieval of $\mathrm{BrO}$

\begin{tabular}{|c|c|c|}
\hline Species & Temperature, $\mathrm{K}$ & Reference \\
\hline Ozone & $203,246,280$ & Voigt et al. [1999] \\
\hline $\mathrm{NO}_{2}$ & 223,280 & Voigt et al. [1999] \\
\hline $\mathrm{O}_{4}$ & 298 & $\begin{array}{l}\text { C. Hermans (personal } \\
\text { communication, 1999) }\end{array}$ \\
\hline $\mathrm{BrO}$ & 228 & Wilmouth et al. [1999] \\
\hline $\mathrm{OClO}$ & 233 & Kromminga et al. [2003] \\
\hline Ring & & Chance and Spurr [1997] \\
\hline
\end{tabular}

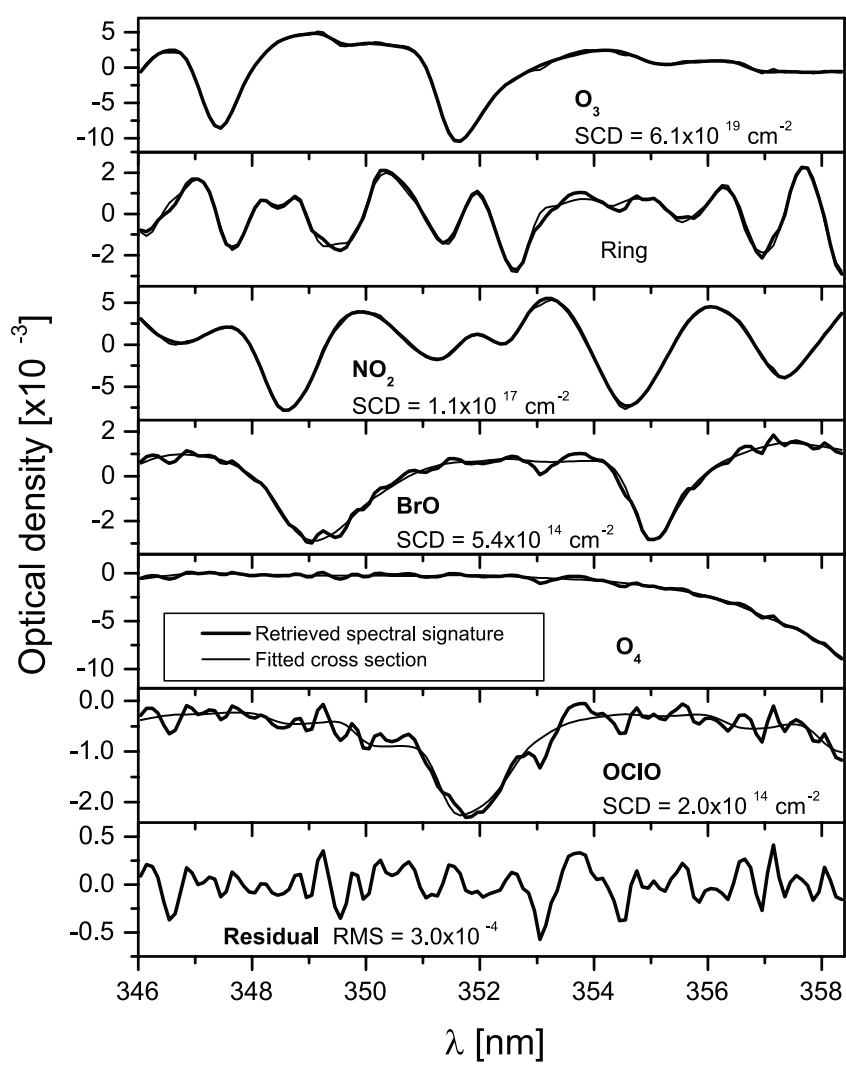

Figure 1. Example for the spectral retrieval of $\mathrm{BrO}$ on 20 September 2000 at $90^{\circ} \mathrm{SZA}$. The Fraunhofer reference spectrum was recorded at noon of 16 October 2000 $\left(66^{\circ} \mathrm{SZA}\right)$. Thick lines, retrieved spectral signature; thin lines, fitted cross section. The slant column densities are denoted in the legends.

background values for $\mathrm{BrO}$ dSCDs during winter are $(2-4) \times 10^{14}$ molecules $/ \mathrm{cm}^{2}$. Some examples for the diurnal variation of the $\mathrm{BrO}$ dSCD and the RMS residual shown in Figure 2 illustrate that $\mathrm{BrO}$ can be clearly detected for solar zenith angles of up to $95^{\circ}$.

[23] Both statistical and systematic error sources contribute to the uncertainties of the measured BrO dSCDs. Under the assumption that the residual of the $\mathrm{BrO}$ analysis has no systematic structures and is only caused by instrumental noise, the statistical error is given by the error of the spectral retrieval, as inferred by equation (14). The retrieval error of the $\mathrm{BrO}$ column during twilight is of the order of $(3-5) \times$ $10^{13}$ molecules $/ \mathrm{cm}^{2}$, corresponding to a relative error of typically $10 \%$ during late autumn and early spring, when the highest stratospheric $\mathrm{BrO}$ amounts are observed. A potential systematic error is caused by an improper relative wavelength alignment of the different cross sections. This error is, however, expected to be negligible since all cross sections were recorded using well-calibrated high-resolution FT spectrometers (see Table 1). An uncertainty in the $\mathrm{BrO}$ cross section of $7.6 \%$ [Wilmouth et al., 1999] causes a further systematic error. In addition, the $\mathrm{BrO}$ cross section strongly decreases with increasing temperature. This can lead to an overestimation of the BrO dSCD of up to $15 \%$ during summer, when the temperature in the lower stratosphere reaches values of up to $240 \mathrm{~K}$, while the $\mathrm{BrO}$ cross 


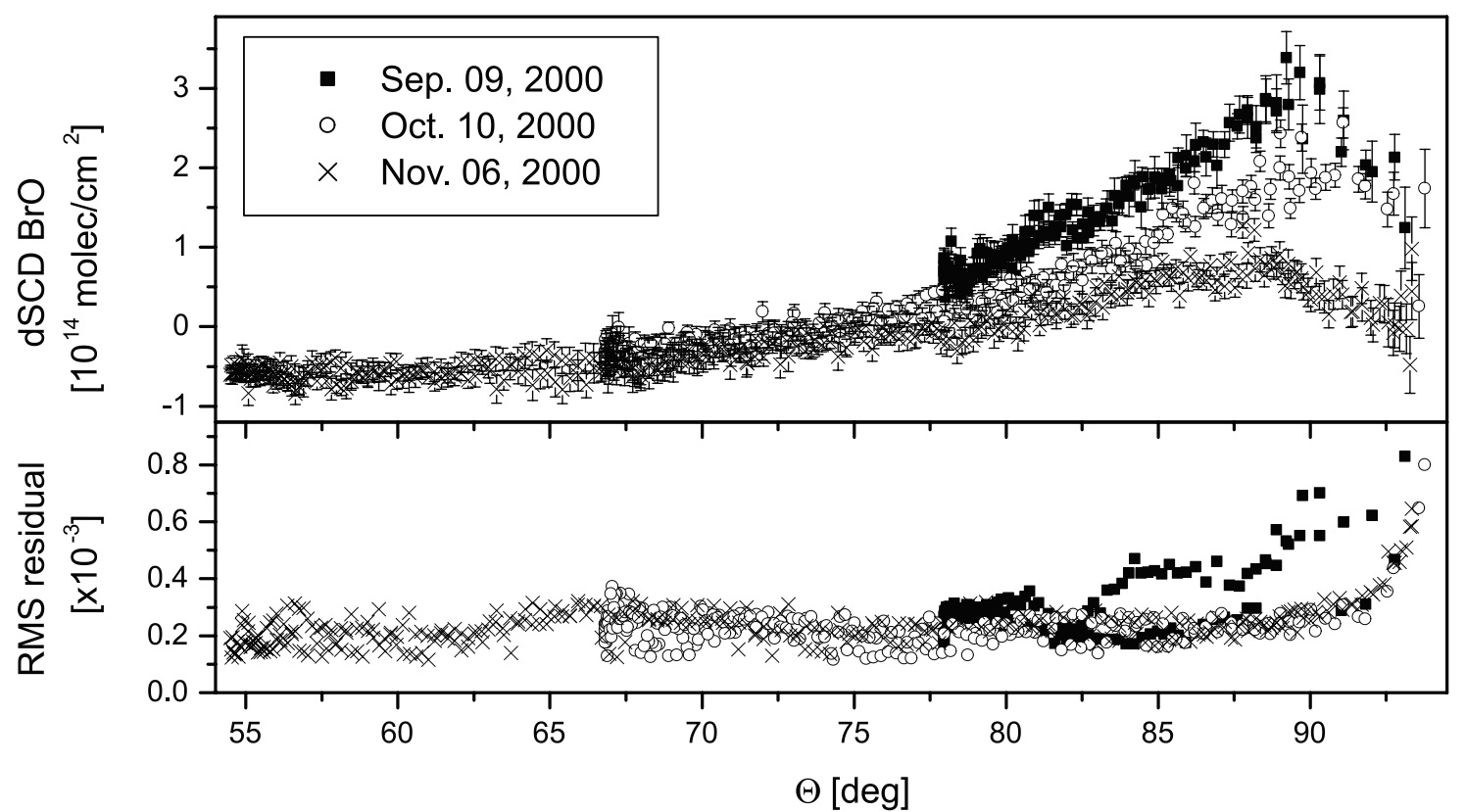

Figure 2. Examples for the variation of the $\mathrm{BrO}$ differential slant column density (upper panel) and residual RMS (lower panel) with SZA during spring 2000. The error bars represent the $1 \sigma$ fit error.

section was recorded at $228 \mathrm{~K}$. This overestimation can be even somewhat higher if a significant fraction of the observed BrO dSCD is located in the lower troposphere.

\subsection{Characterization of the Tropospheric Light Path Using $\mathrm{O}_{4}$ Absorption}

[24] For a given vertical distribution of a trace gas the observed slant column density is determined by the light path through the atmosphere. Thus multiple Mie scattering on atmospheric particles, such as clouds and/or snow drift, can strongly enhance the observed dSCD if a significant fraction of the trace gas is located at low altitudes. In the presence of near-surface $\mathrm{BrO}$ this implies that the tropospheric part of the dSCD can be strongly amplified in the presence of clouds or snow drift, while the stratospheric part of the dSCD is not or only slightly affected. The enhancement of the light path in the lower troposphere can be quantified spectroscopically using an absorber with a known vertical concentration profile. Here we use the absorption features of the oxygen dimer $\left(\mathrm{O}_{4}\right)$ for the detection of near-surface multiple scattering. Since $\mathrm{O}_{4}$ is the collision complex of two $\mathrm{O}_{2}$ molecules [Greenblatt et al., 1990; Van Roozendael et al., 1994], its concentration is proportional to the square of the air density. The $\mathrm{O}_{4}$ profile is therefore located in the lower troposphere with a scale height of $\sim 3.5 \mathrm{~km}$ in polar regions.

[25] It is important to note that the variation of radiative transfer with wavelength strongly depends on the amount, properties, and location of particles in the troposphere [Wagner et al., 2002]: the cross section of Rayleigh scattering is proportional to $\lambda^{-4}$, while scattering on large particles (water droplets or ice particles) is almost independent of wavelength. We therefore use the optical density of the strong $\mathrm{O}_{4}$ absorption band located close to the wavelength region of the $\mathrm{BrO}$ retrieval (centered at $361 \mathrm{~nm}$ ) to characterize the influence of near-surface multiple scattering on the observed $\mathrm{BrO}$ dSCD. The $\mathrm{O}_{4}$ retrieval is performed using the same set of cross sections as for $\mathrm{BrO}$ but in the wavelength interval between 350 and $370 \mathrm{~nm}$.

[26] For weak absorbers (such as $\mathrm{BrO}$ and $\mathrm{O}_{4}$ ) the air mass factor (AMF), defined as the ratio of the vertical column density (VCD) and the SCD, is influenced by the shape of the trace gas profile. Therefore near-surface $\mathrm{BrO}$ has not necessarily the same AMF as $\mathrm{O}_{4}$. However, the diurnal variation of the clear-sky $\mathrm{AMFs}$ for $\mathrm{BrO}$ located in the lowermost troposphere and for $\mathrm{O}_{4}$ are in reasonable agreement (see Figure 3) [Marquard et al., 2000]. This finding gives confidence that an increase in $\mathrm{O}_{4} \mathrm{dSCD}$ is a suitable indicator for the enhancement of the $\mathrm{BrO}$ AMF owing to an increase in light path, although the tropospheric $\mathrm{BrO}$ AMF may differ from the $\mathrm{O}_{4}$ AMF under particular circumstances, e.g., if tropospheric $\mathrm{BrO}$ is entirely located above or below the layer where multiple scattering occurs. A cloud located above the instrument acts as a diffusor. Therefore BrO located above a cloud leads to an tropospheric AMF similar to direct light observations, while the light traverses the $\mathrm{BrO}$ layer vertically if $\mathrm{BrO}$ is located below a cloud, leading to a slight decrease in AMF.

[27] To quantify the light path enhancement in the lower troposphere owing to multiple scattering, we define the light path enhancement factor $\mathrm{L}$ as the ratio between the $\mathrm{O}_{4}$ absorption coefficient $C_{O_{4}}(\Theta)$ at a given SZA $\Theta$ and the average $\mathrm{O}_{4}$ absorption coefficient at the same SZA under clear-sky conditions $\overline{C_{O_{4}}^{c l}}(\Theta)$ :

$$
L(\Theta)=\frac{C_{O_{4}}(\Theta)}{\overline{C_{O_{4}}^{c l}}(\Theta)} .
$$

[28] The calculation of $\overline{C_{O_{4}}^{c l}}(\Theta)$ requires the identification of clear-sky conditions, which is done using the following criteria: (1) a "smooth" diurnal variation of $\mathrm{O}_{4}$ without 


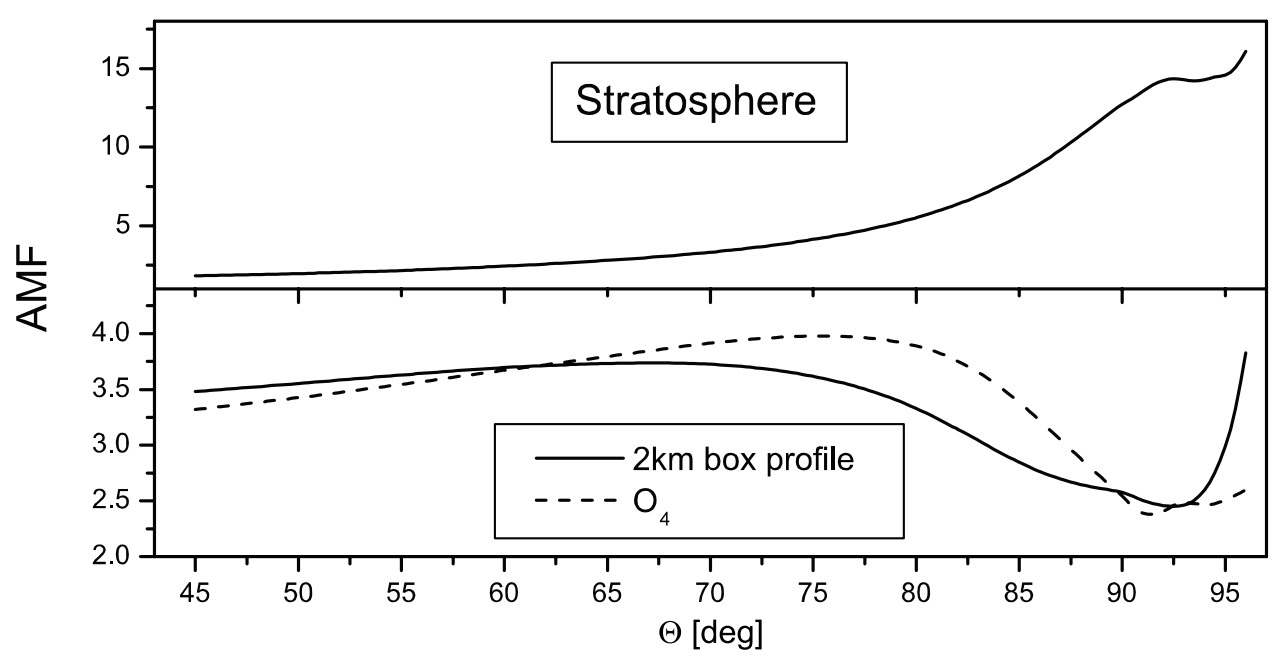

Figure 3. Air mass factor at $\lambda=349 \mathrm{~nm}$ for a stratospheric absorber with a constant mixing ratio above the tropopause (upper panel) and for a tropospheric absorber with a constant mixing ratio in the lowermost $2 \mathrm{~km}$ (lower panel, solid line). Dashed line, $\mathrm{O}_{4}$ air mass factor at $361 \mathrm{~nm}$. The air mass factors are calculated using the AMFTRAN multiple scattering Monte Carlo model [Marquard et al., 2000].

short-term variations, (2) smaller $\mathrm{O}_{4}$ absorption coefficients compared to periods with clouds or snow drift, and (3) much smaller values and a "smooth" temporal variation of the light intensity on clear days compared to periods where multiple scattering dominates.

[29] Using these criteria, only 26 clear-sky days were identified in 1999. The examples for the different variations of the $\mathrm{O}_{4}$ absorption and light intensity with SZA shown in Figure 4 illustrate that clear-sky conditions and conditions with clouds or snow drift can be clearly distinguished by eye.

[30] The benefit of the light path enhancement factor for the interpretation of observations of tropospheric trace gases is illustrated in Figure 5, where examples for the relation- ship between light path enhancement and $\mathrm{BrO}$ dSCDs are shown. Light path enhancement factors ranging from 2 to 4 at are observed on the morning of 13 September 1999. The simultaneous increase in $\mathrm{BrO} \mathrm{dSCD}$ compared to the evening values indicates that the observed enhancement is of tropospheric origin and that at least a part of the tropospheric $\mathrm{BrO}$ profile is located at altitudes where multiple scattering occurs. In contrast, no relationship between the light path enhancement and the BrO dSCD is detected at the morning of 27 September 1999, although similar light path enhancement factors as on 13 September are observed. This strongly suggests that the majority of the detected $\mathrm{BrO}$ is located in the stratosphere. The correlation of light path enhancement factor and $\mathrm{BrO}$ dSCD during
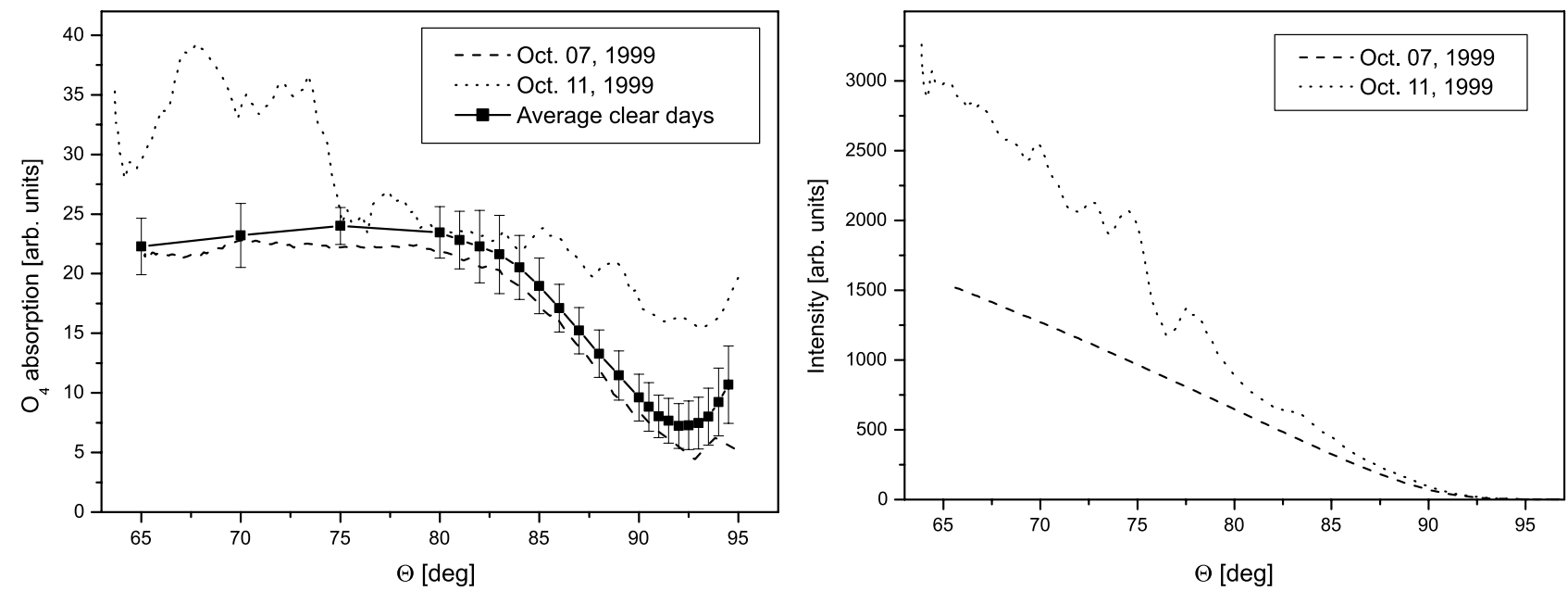

Figure 4. Diurnal variation of $\mathrm{O}_{4}$ (left panel) and intensity (right panel), observed under clear-sky (7 October 1999, dashed lines) and cloudy sky conditions 11 (October 1999, dotted lines). Also shown is the average $\mathrm{O}_{4}$ absorption during spring 1999 (solid line). The error bars indicate the standard deviation of the data. 


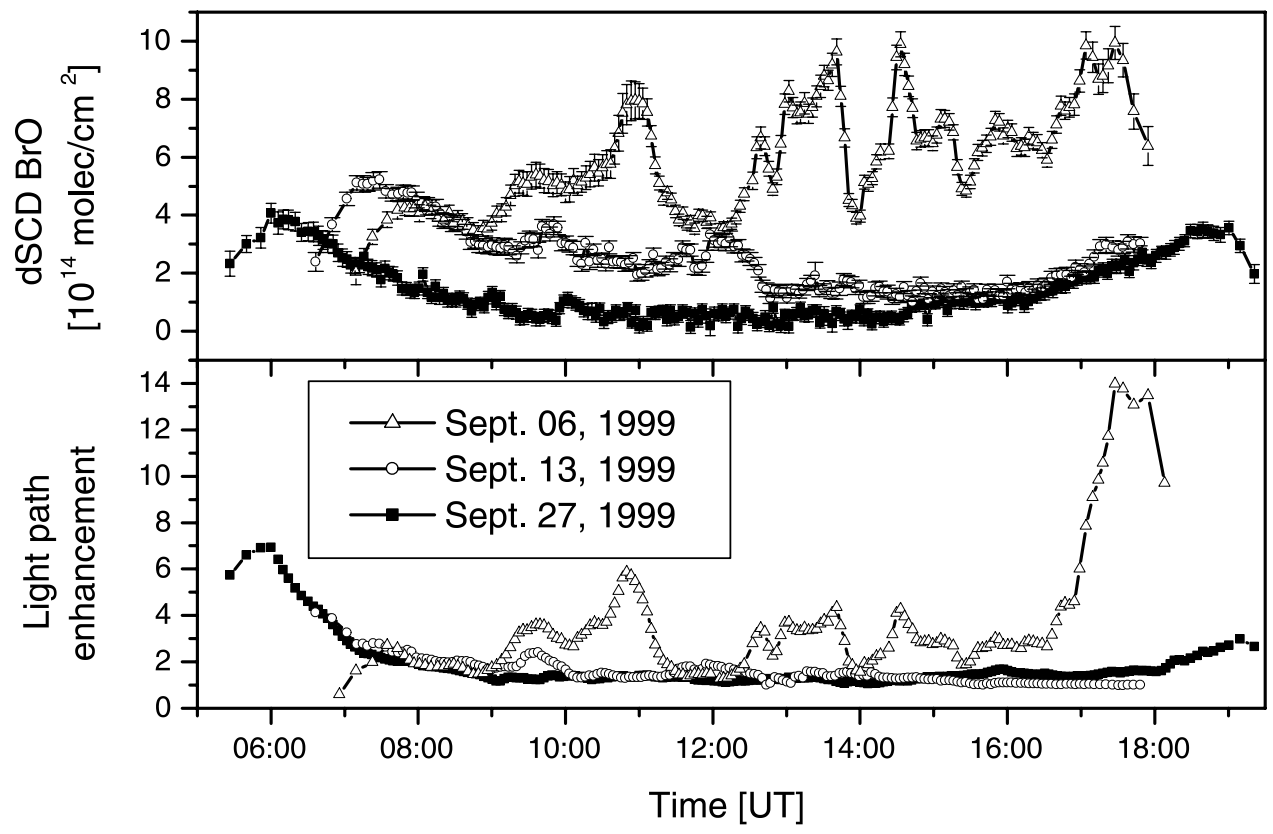

Figure 5. Examples for the relationship between the $\mathrm{BrO} \mathrm{dSCD}$ and the light path enhancement, observed on 6, 1, 3 and 27 September 1999.

tropospheric $\mathrm{BrO}$ events can be seen more clearly on 6 September 1999, where high and variable light path enhancement factors correlate well with the observed $\mathrm{BrO}$ dSCDs. Reflecting the amplification of the observed tropospheric $\mathrm{BrO}$ column, the light path enhancement leads to BrO dSCDs of more than $1 \times 10^{15}$ molecules $/ \mathrm{cm}^{2}$.

[31] In summary, a "U"-shaped diurnal variation of the $\mathrm{BrO}$ dSCD is observed in situations when $\mathrm{BrO}$ is entirely located in the stratosphere (owing to the increase in stratospheric air mass factor at twilight), while the presence of tropospheric $\mathrm{BrO}$ leads to a strong variability proportional to the light path enhancement factor L. However, nearsurface $\mathrm{BrO}$ is difficult to detect under clear-sky conditions $(L=1)$. In this case it only adds a constant factor to the stratospheric dSCD owing to the weak dependency of the tropospheric air mass factor on SZA compared to the stratospheric AMF (see Figure 3).

\subsection{Ozone Measurements}

[32] Surface ozone mixing ratio is measured at the Neumayer trace gas observatory by a commercial ozone monitor (Anysco O3 41M), which is based on short-path absorption. Data is available at a temporal resolution of $1 \mathrm{~min}$, with an accuracy of $0.2 \mathrm{ppb}$ and a detection limit of $\approx 1 \mathrm{ppb}$.

[33] Vertical profiles of temperature and ozone partial pressure in the lower troposphere are derived from the regular ozone soundings at Neumayer station. Ozone sondes are launched once per week throughout the year and more frequently during the ozone hole period in September and October (2-3 launches per week). The ozone concentration is measured by pumping air through an electrochemical concentration cell (type ECC 6A). A potassium iodide solution reacts with the ozone molecules, leading to a change in electric current from which the ozone concentration can be inferred. The accuracy of the ozone measurements in the troposphere better than $<10 \%$. Temperature profiles are measured with an accuracy of $0.2 \mathrm{~K}$. The vertical resolution of the profile data is $\sim 25 \mathrm{~m}$.

\subsection{Trajectory Analysis}

[34] Since sea-salt surfaces are believed to be the origin of reactive bromine released by heterogeneous processes, it can be expected that air masses depleted in ozone originate from the sea ice covered ocean. However, no clear relationship between surface ozone depletion events and wind direction and speed are observed at Neumayer. Air masses low in ozone are not significantly correlated with northerly wind directions, which would indicate that the air masses come from the sea ice. Short periods of northerly winds often occur at the beginning of ozone depletion events, but ozone remains low despite changes in wind direction. Obviously, the local wind direction is not suitable to characterize the medium and long-range transport of air masses. Easterly winds dominate [König-Langlo et al., 1998], while katabatic winds coming from the Antarctic plateau are rarely observed at Neumayer. The origin of the air masses reaching the station is strongly affected by the large-scale meteorological situation, with air masses originating from the sea ice being mostly related to cyclonic activity over the south polar sea [Kottmeier and Fay, 1998]. It is therefore necessary to take the large-scale meteorological situation into account to determine the origin of air masses reaching Neumayer station.

[35] Back trajectory calculations are a commonly used technique to gain information on the sources of air masses arriving at a specific location. However, back trajectory calculations in connection with $\mathrm{BrO}$ events have only been performed for some selected cases [e.g., Roscoe et al., 2001; Ridley et al., 2003; Evans et al., 2003].

[36] We will demonstrate in the following that trajectory calculations of high temporal and vertical resolution in connection with sea ice maps can be a powerful technique 
for the interpretation of tropospheric $\mathrm{BrO}$ events. To determine the source regions of the bromine containing and ozone-depleted air masses, we use the Hybrid SingleParticle Lagrangian Integrated Trajectory (HYSPLIT) model [Draxler and Hess, 1997; Draxler, 1999] to calculate trajectories in high temporal and vertical resolution. This trajectory model can process various meteorological data sets. Trajectories can be calculated on isentropic, isobaric, and constant air density surfaces or by using the modeled vertical motion given by the meteorological input data. The latter option is used within this study since it is expected to produce the most reliable results.

[37] The FNL meteorological data set [Stunder, 1997] serves as input data for the HYSPLIT trajectory model. The 6-hourly FNL archive data on a $1^{\circ}$ latitude-longitude grid is an operational product of the Global Data Assimilation System (GDAS), provided by the National Center of Environmental Prediction (NCEP) [Kanamitsu, 1989; Derber et al., 1991; Parrish and Derber, 1992]. Meteorological fields are provided at 14 pressure levels, with 6 levels being located between the surface and $500 \mathrm{mBar}$ $(\approx 5000 \mathrm{~m})$.

[38] For August and September of 1999 and 2000, 5-day back trajectories are calculated in time steps of 1 hour and altitude steps of $100 \mathrm{~m}$ from the ground up to an altitude of $5000 \mathrm{~m}$. Using these 74.000 trajectories, we determine the time each air parcel was located close to the sea ice surface using sea ice maps of the south polar ocean provided by NCEP. The sea ice coverage is measured using a passive microwave instrument aboard the Defense Meteorological Satellite Program [Goodberlet and Swift, 1992].

[39] We define the duration of sea ice contact $\tau(T, h)$ as the time an air parcel was located over the sea ice at an altitude below the threshold value $z_{0}$ during the last 5 days before it reaches the Neumayer station at the time $T$ at an altitude $h$. The threshold altitude was set to $z_{0}=100 \mathrm{~m}$ since it can be assumed that the air is well mixed in this layer close to the surface so that an uptake of reactive bromine or sea-salt aerosols from sea ice is possible. The sea ice coverage is adapted from NCEP sea ice maps, with regions covered by ice at the end of February being not considered as sea ice. This excludes shelf ice as well as more than 1 year old sea ice, which has too low salinity for the release of reactive bromine [Lehrer, 1999], from the calculation of $\tau$. The inferred durations of sea ice contact are found to vary only slightly if $z_{0}$ were set to higher altitudes.

[40] An example for the determination of the duration of sea ice contact is shown in Figure 6. The trajectories are ending on $T=2$ September 1999, 18:00 at altitudes of $h=0$, 500 , and $1000 \mathrm{~m}$ above the Neumayer station. The lowermost trajectory comes from the Antarctic continent and thus had no contact to the sea ice: $\tau(T, h=0)=0$ hours. The $500 \mathrm{~m}$ trajectory has passed the sea ice in an altitude below $100 \mathrm{~m}$ for 53 hours, started to ascend 30 hours prior to the arrival at Neumayer, and traveled along the coast line before reaching the station: $\tau(T, h=500 \mathrm{~m})=53$ hours. The trajectory ending at $1000 \mathrm{~m}$ came from the open sea and reached the sea ice edge at $t=-96$ hours. The air parcel stayed over the sea ice at an altitude $z<z_{0}$ and started to ascend 2 days prior to the arrival at Neumayer: $\tau(T, h=$ $1000 \mathrm{~m})=44$ hours.

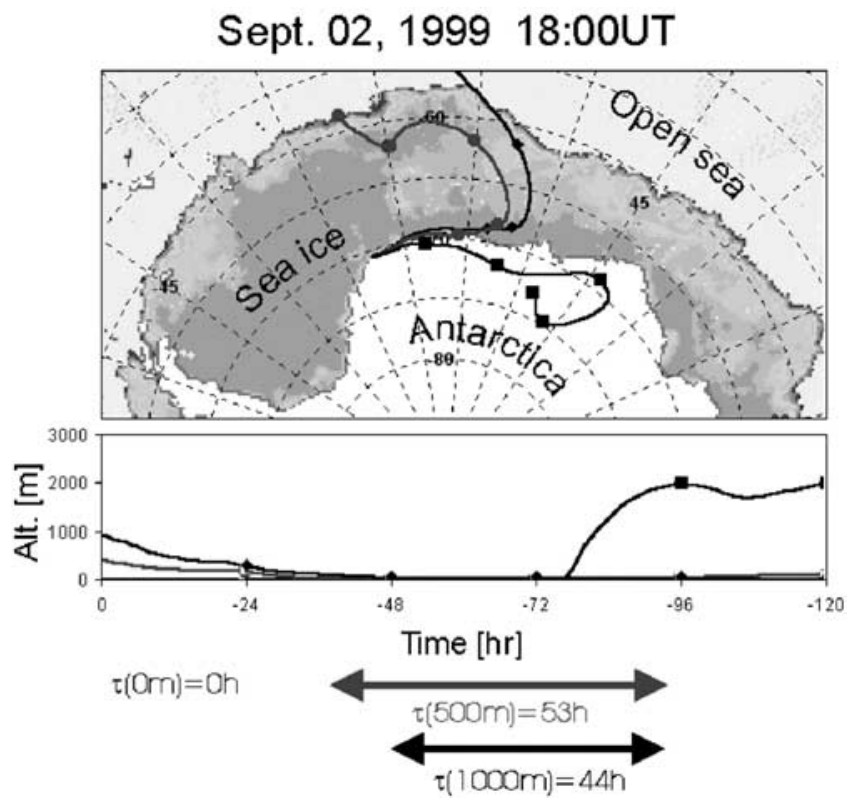

Figure 6. Example for the determination of the duration of sea ice contact. The 120 hour back trajectories ending at altitudes of 0,500 , and $1000 \mathrm{~m}$ at the Neumayer station on 2 September 1999, 18:00, are indicated by squares, circles, and diamonds, respectively. The sea ice coverage from NCEP is shown as dark shaded areas, the open sea is shown as light shaded areas.

[41] An intercomparison of three trajectory models applied to Arctic haze has shown that both the parameterizations of the vertical motion and the meteorological data set on which the trajectory modeling is based contribute substantially to the overall uncertainty of the inferred trajectories [Kahl et al., 1989]. A detailed analysis of trajectories in the Antarctic lower troposphere [Kottmeier and Fay, 1998] shows that the errors owing to atmospheric wind shear and interpolation errors of the vertical wind component may lead to position uncertainties in the trajectories of up to $1000 \mathrm{~km}$ after 5 days integration time. However, the uncertainties in the horizontal position are not the limiting factor in the accuracy of the inferred duration of sea ice contact since its calculation is based only on distinguishing between air masses originating from the continent, the sea ice, and the open sea. Uncertainties mainly arise if air parcels travel along the coast line of Antarctica. Of more importance is the uncertainty in altitude of the air parcels, which depends on how realistic advection processes are represented in the trajectory model and the meteorological data set. In addition, no mixing processes are taken into account in the trajectory analysis. Therefore air parcels traveling along the coast line or in altitudes above the threshold altitude of $z_{0}=100 \mathrm{~m}$ may be depleted in ozone or contain reactive bromine owing to horizontal or vertical mixing processes, although the calculated duration of sea ice contact is zero.

\subsection{GOME BrO Measurements}

[42] We compare the ground-based DOAS measurements of $\mathrm{BrO}$ with $\mathrm{BrO}$ maps of the Southern Hemisphere from the Global Ozone Monitoring Experiment (GOME) aboard 


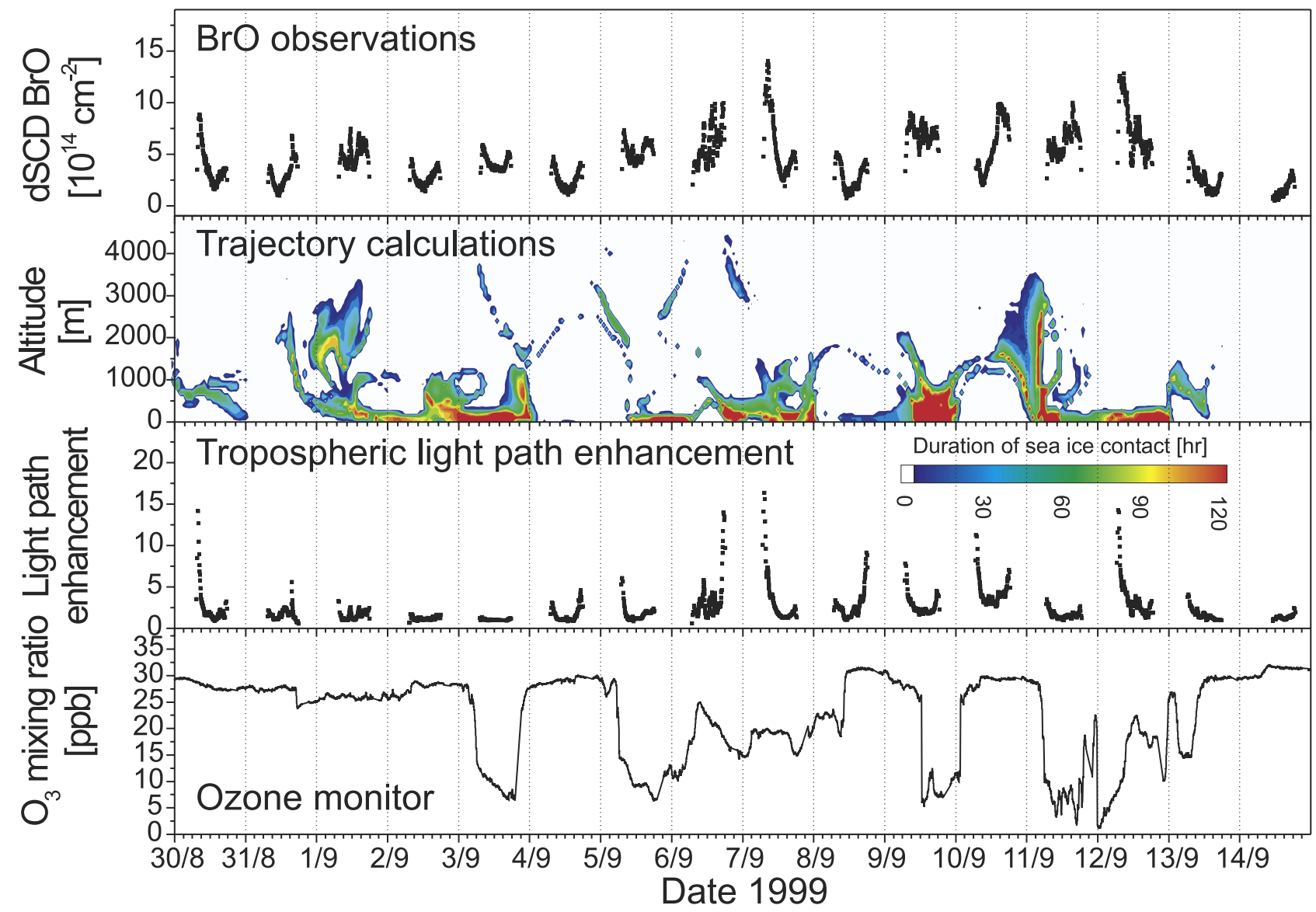

Figure 7. Observations of enhanced BrO from 30 August to 15 September 1999: BrO dSCD, duration of sea ice contact, light path enhancement factor, and surface ozone mixing ratio. See text for further explanation.

the European research satellite ERS-2. The GOME instrument consists of a set of four spectrometers. They simultaneously measure the sunlight reflected from Earth's atmosphere and from the ground in four spectral windows covering the wavelength range between 240 and $790 \mathrm{~nm}$ with moderate spectral resolution $(0.2-0.4 \mathrm{~nm}$ full width at half maximum (FWHM)). The satellite operates in a nearly polar, Sun-synchronous orbit at an altitude of $780 \mathrm{~km}$ with a local equator crossing time at approximately 10:30. During one sweep, three individual spectra are recorded. These correspond to three ground pixels that lie side by side with a typical size of $40 \mathrm{~km}$ (along track, i.e., in north-south direction) times $320 \mathrm{~km}$ (across track) each. Poleward from about $70^{\circ}$ latitude, global coverage is achieved daily [Wagner and Platt, 1998]. Starting from calibrated spectra, we apply the DOAS method and radiative transport for a purely stratospheric $\mathrm{BrO}$ background to get total $\mathrm{BrO}$ vertical columns [Wagner et al., 2001]. In this analysis we restrict the solar zenith angle to be less than or equal to $90^{\circ}$. We also apply a diffuser-plate correction [Richter et al., 1998] to remove its artificial spectral structure although this is of minor importance for polar columns.

\section{Results}

[43] Data from periods in Austral spring with numerous $\mathrm{BrO}$ enhancements (30 August to 14 September 1999 and
11-26 September 2000) are shown in Figures 7 and 8, respectively. $\mathrm{BrO} \mathrm{dSCDs}$ are shown together with the duration of sea ice contact as determined using the trajectory calculations, the tropospheric light path enhancement from $\mathrm{O}_{4}$ measurements, and the surface ozone mixing ratio. The duration of sea ice contact $\tau(T, h)$ for air parcels arriving at Neumayer station at a given time $T$ ( $x$ axis) and altitude $h$ ( $y$ axis) is shown as a contour plot, with white areas representing air parcels without sea ice contact during the last 5 days $(\tau=0)$.

[44] Between 31 August and 2 September 1999 the trajectory calculations indicate that air masses on the ground originated from the sea ice. Also, elevated levels of $\mathrm{BrO}$ are observed, but only a very slight $(<2.5 \mathrm{ppb})$ decrease in surface ozone mixing ratio occurs. The trajectories shown in Figure 9 indicate that the particular meteorological conditions during this period may be responsible for this finding: the center of a cyclone is located close to the Neumayer station, causing the air masses to circulate within a small region over the sea ice north of the observation site. However, it remains unclear why no ozone depletion occurs under these circumstances although tropospheric $\mathrm{BrO}$ is detected. It is possible that the trajectories of air masses close to the surface are not well captured by the meteorological model: the slow descent of air masses with sea ice contact on 31 August and the morning of 1 September might not reach the surface until 3 September. 


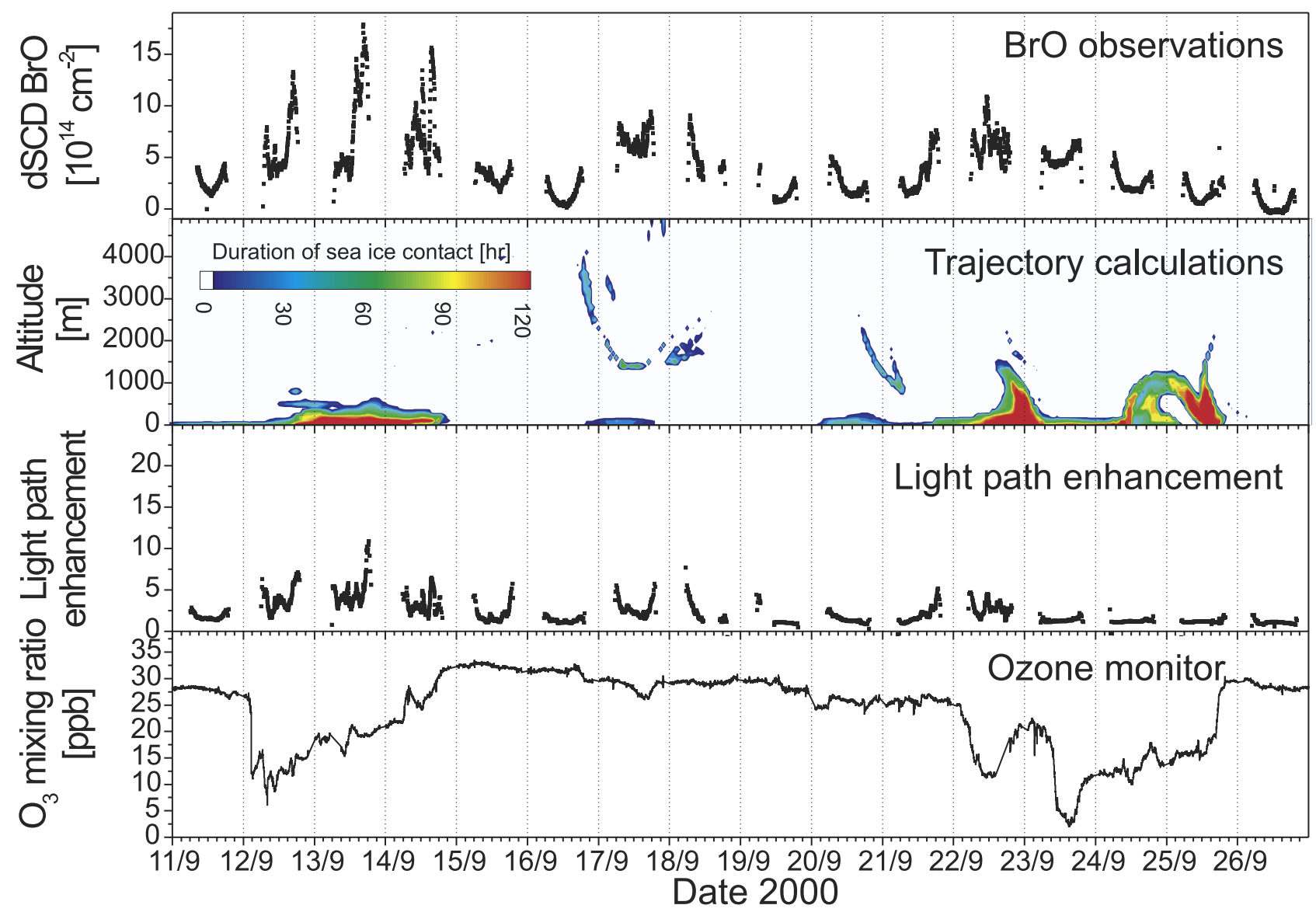

Figure 8. Same as Figure 7, but for 11-27 September 2000.

[45] Severe ozone depletion events occur between 3 and 13 September 1999 and 22 and 26 September 2000, with surface ozone mixing ratios dropping below $5 \mathrm{ppb}$ on 11 and 12 September 1999 (Figure 7) and 23 September 2000 (Figure 8). These periods coincide with transport of air masses with long sea ice surface contact times to the measurement site. Surface ozone destruction is only observed if air masses probed at ground originate from the sea ice surface. The simultaneous increase in $\mathrm{BrO}$ dSCD indicates that bromine-activated air masses are present at the observation site. However, strong $\mathrm{BrO}$ enhancements also occur in the absence of surface ozone depletion, e.g., on 10 September 1999, when air masses previously exposed to sea ice were transported to high altitudes (between 1000 and $4000 \mathrm{~m}$ ). This strongly suggests that reactive bromine is present above the boundary layer. These air masses descend during the afternoon and surface ozone destruction is initiated as these bromine-activated air masses reach the ground at morning on 11 September. A similar pattern suggesting an uplift of bromine-activated air is observed on 31 August to 1 September 1999, and the trajectory calculations indicate numerous filaments of air coming from the sea ice at altitudes above $2000 \mathrm{~m}$ during 3-8 September 1999 and 16-18 September 2000. Some periods with typical background surface ozone levels of about $30 \mathrm{ppb}$ (on 4 and 8 September, the morning of 10 September 1999, and 16, 19, and 26 September 2000) agree very well both with the trajectory calculations, which indicate that the air masses arriving at the surface have no or only short $(<20$ hours) contact with sea ice and with the BrO SCDs, which show a "U"-shaped diurnal variation typical for $\mathrm{BrO}$ being exclusively located in the stratosphere (and possibly in the free troposphere).

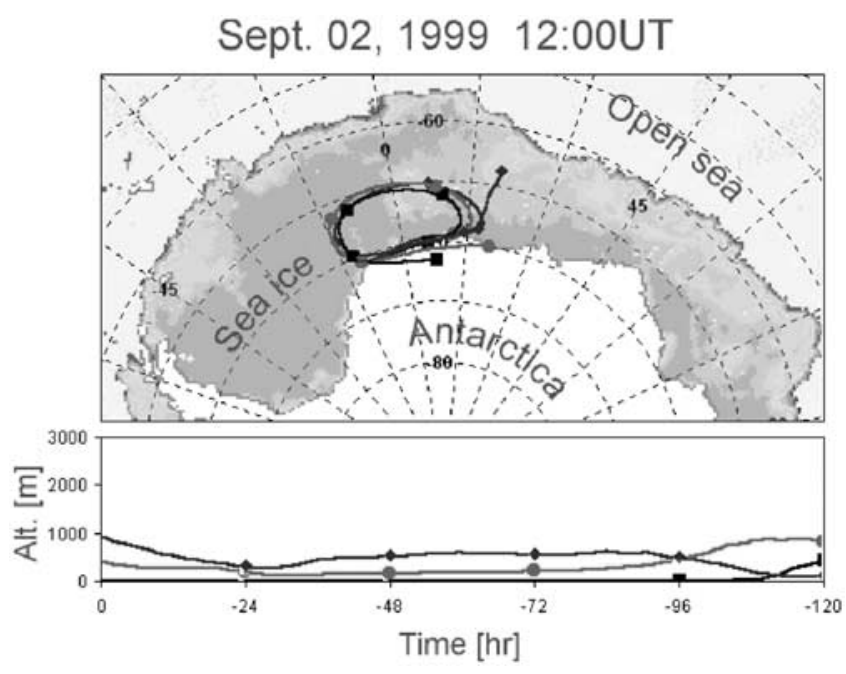

Figure 9. Trajectories ending at Neumayer station on 2 September 1999, 12:00 UT at 0, 500, and $1000 \mathrm{~m}$ altitude. 


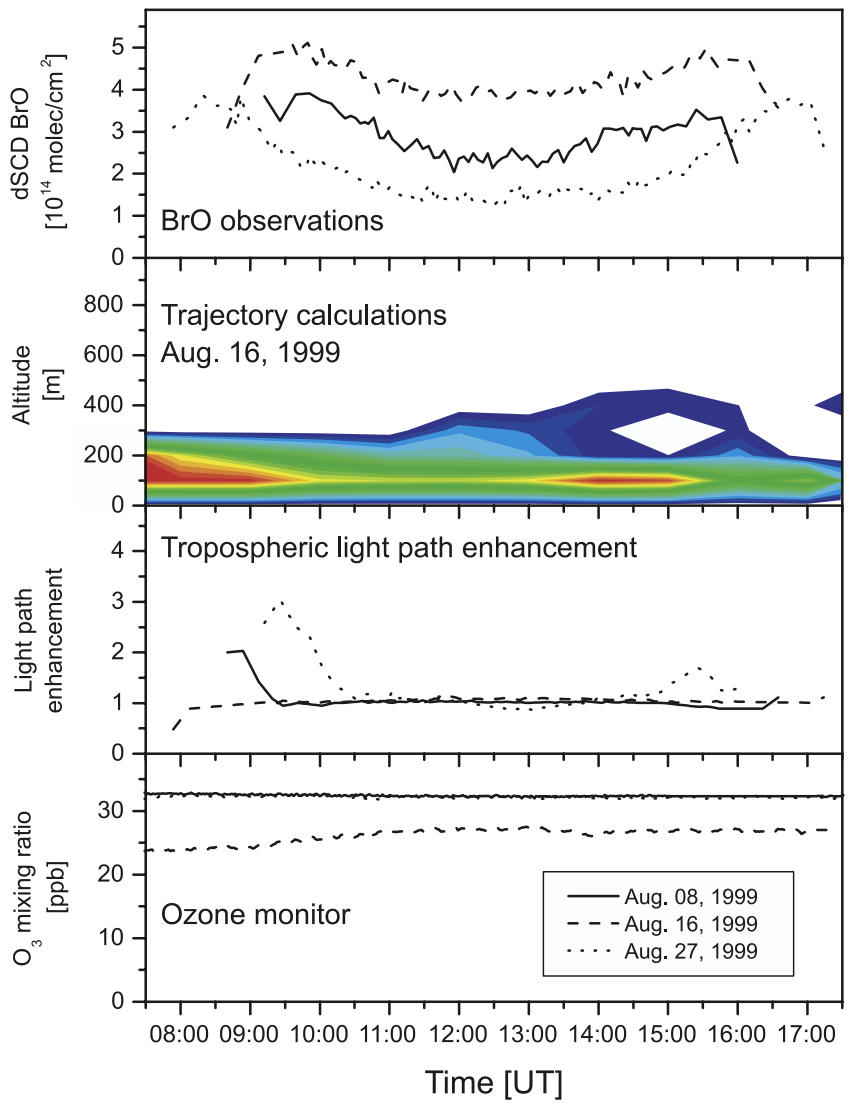

Figure 10. $\mathrm{BrO} \mathrm{dSCD}$, light path enhancement, and surface ozone mixing ratio on 8, 16, and 27 August 1999. The duration of sea ice contact is shown only for 16 August. No air masses with sea ice contact were present on 8 and 27 August.

[46] Most periods of elevated $\mathrm{BrO}$ are accompanied by strong enhancements in $\mathrm{O}_{4}$ absorption, while the light path enhancement factor usually remains low in the absence of $\mathrm{BrO}$ events. This coincidence between an increase in tropospheric light path, air masses coming from the sea ice, and the detection of bromine activation may indicate that sea-salt aerosols are transported from the sea ice surface to Neumayer station. If this is the case, recycling of reactive bromine on sea-salt surfaces could still take place in the probed air masses.

[47] $\mathrm{BrO}$ enhancements under clear-sky conditions (i.e., periods with light path enhancement factors of $L \approx 1$ ) are rarely observed. One example allowing us to investigate the influence of tropospheric $\mathrm{BrO}$ on the observed diurnal variation for conditions when the radiative transport is not dominated by multiple scattering occurs on 16 August 1999. As shown in Figure 10, no light path enhancement was detected on this day, allowing for a rough estimation of the tropospheric $\mathrm{BrO}$ mixing ratio. Also shown in Figure 10 are the $\mathrm{BrO}$ dSCDs on 8 and 27 August 1999. It is very likely that no tropospheric $\mathrm{BrO}$ is abundant on the latter two days since the duration of sea ice contact above Neumayer is zero and surface ozone remains high $(\approx 32 \mathrm{ppb})$.

[48] The diurnal variations of the BrO dSCD shown in Figure 10 have a "smooth" shape, but the dSCD is increased by a constant factor on 16 August compared to the observations of mainly stratospheric $\mathrm{BrO}$ on the other 2 days. Furthermore, significantly reduced surface ozone mixing ratios of less than $27 \mathrm{ppb}$ and the presence of air from sea ice surfaces in the boundary layer on 16 August indicate that reactive bromine present at the observation site is responsible for the constant increase in $\mathrm{BrO} d \mathrm{dSCD}$. The lack of short-term variability indicates that $\mathrm{BrO}$ is homogeneously distributed within the boundary layer. The $\mathrm{BrO}$ dSCDs at $87^{\circ}$ SZA (corresponding to a tropospheric air mass factor of 3.14; see Figure 3) on 8 and 27 August are $2.75 \times 10^{14}$ and $2.3 \times 10^{14}$ molecules $/ \mathrm{cm}^{2}$, respectively (a decrease that can be attributed to the seasonal variation of stratospheric $\mathrm{BrO}$ ), compared to $4.3 \times 10^{14}$ molecules $/ \mathrm{cm}^{2}$ on 16 August. Assuming that the stratospheric part of the $\mathrm{BrO}$ dSCD on 16 August is the average of the dSCDs observed on 8 and 27 August yields a tropospheric $\mathrm{BrO}$ SCD of $1.8 \times 10^{14}$ molecules $/ \mathrm{cm}^{2}$. A boundary layer height on 16 August of $1500 \mathrm{~m}$, inferred from radiosonde data, and the assumption that $\mathrm{BrO}$ is uniformly distributed within the boundary layer yield a tropospheric mixing ratio of approximately $13 \mathrm{ppt}$, a value of the same order of magnitude as previously observed in the Arctic, e.g., by Tuckermann et al. [1997] (up to $20 \mathrm{ppt}$ ) and Hönninger and Platt [2001] ( $\approx 30 \mathrm{ppt})$.

[49] Examples for vertical structure of tropospheric ozone depletion events are shown in Figure 11, where data from two ozone soundings during periods of elevated $\mathrm{BrO}$ are compared with the duration of sea ice contact as a function of altitude. On 30 August 1999 a significant decrease in ozone partial pressure of about $25 \%$ compared to background values occurs at altitudes between 700 and $1500 \mathrm{~m}$. The trajectory calculations indicate that this ozone destruction is caused by air masses coming from sea ice surfaces, with durations of sea ice contact of about 50 hours for air parcels arriving in an altitude range between 500 and $1000 \mathrm{~m}$. The simultaneous increase in $\mathrm{BrO}$ dSCD (see Figure 7) indicates that reactive bromine is present in this

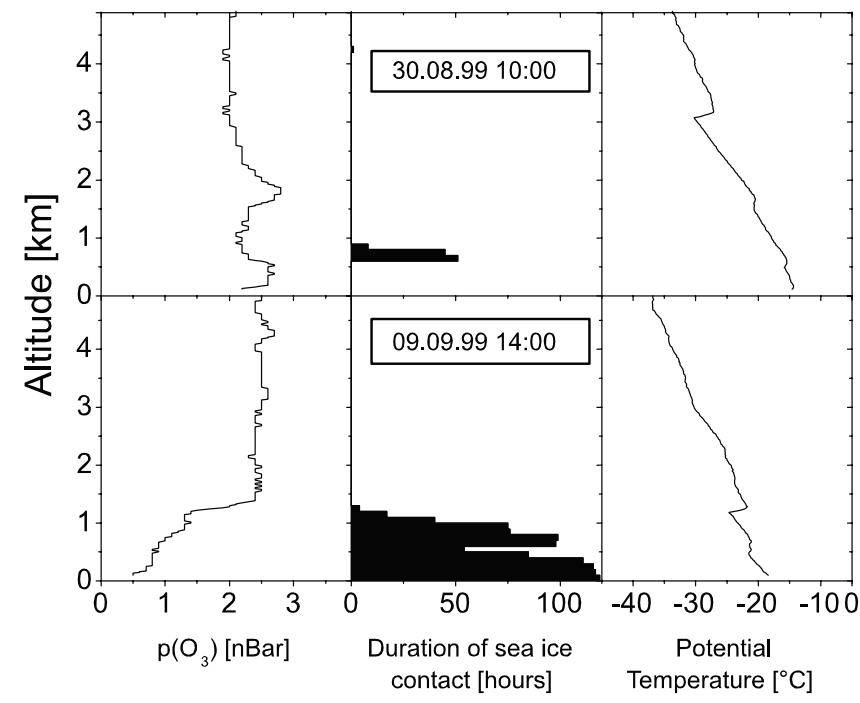

Figure 11. Vertical profiles of ozone partial pressure (left panel) and potential temperature (right panel) from ozone soundings on 30 August and 9 September 2000, together with the duration of sea ice contact as a function of altitude (middle panel). 

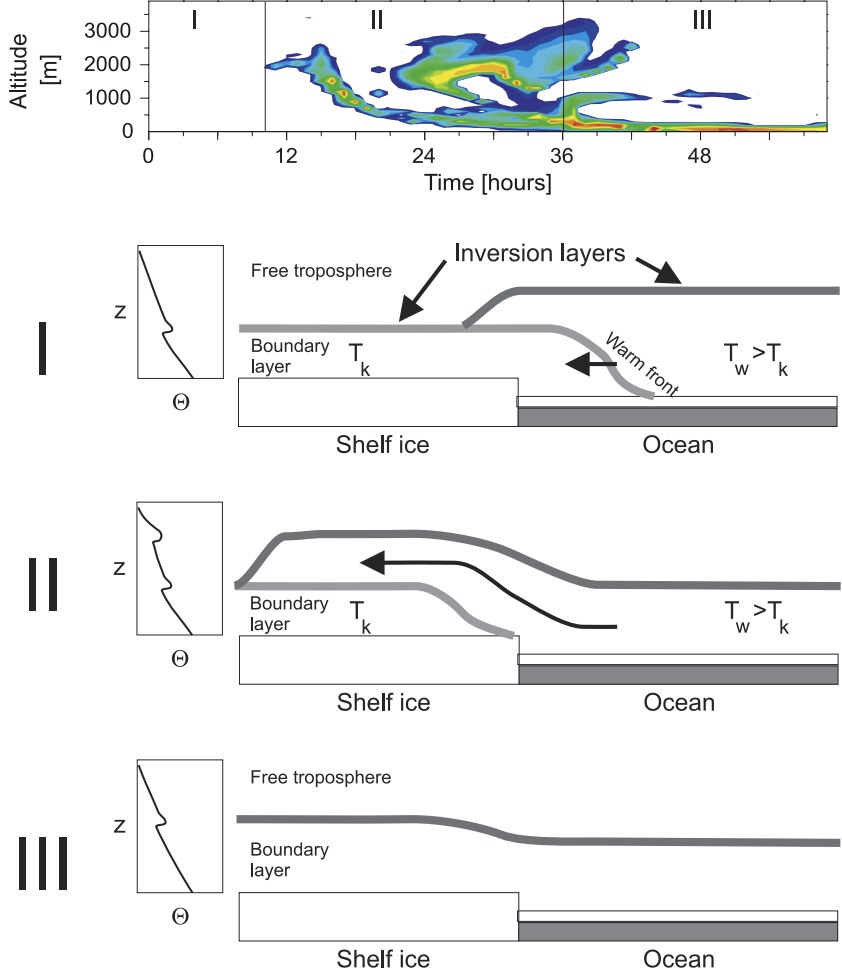

Figure 12. Upper panel: typical pattern of the duration of sea ice contact at the beginning of an ozone depletion event observed on 15-19 September 1999. Lower three panels: sketch drawing of the vertical profile of potential temperature (left) and latitudinal cross section of the atmosphere (right). For more details, see text.

layer. The vertical profile of potential temperature shows that ozone-depleted air masses are confined between two strong inversion layers. It is therefore likely that the observed upward transport of air masses from the sea ice into the free troposphere is caused by advection of warm air from the sea over the cold and stable boundary layer at the shelf ice. These processes will be discussed in more detail below. Ozone depletion on 9 September 1999 extends from the surface up to altitudes of $\sim 1100 \mathrm{~m}$, where a strong inversion layer prevents air from mixing between the boundary layer and free troposphere. Again, the trajectory calculations show that the ozone depletion within the boundary layer is caused by air with a duration of sea ice contact of up to 120 hours, causing a strong $\mathrm{BrO}$ enhancement (see Figure 7).

[50] An example for a frequently observed pattern of the duration of sea ice contact at the beginning of a surface ozone destruction event is shown in the upper panel of Figure 12: Starting at altitudes of $\approx 2000 \mathrm{~m}$, air masses coming from the sea descend to the ground within 12 24 hours. Surface ozone depletion is observed when these air masses touch the ground. On the basis of the analysis of FNL meteorological maps, our observations suggest the following meteorological scenario sketched in the lower panels of Figure 12: (I) Driven by an eastward moving cyclone passing north of the Neumayer station, a warm front located over the sea ice moves southward. (II) The boundary layer over the shelf ice is very stable owing to a strong inversion layer in the lowermost troposphere. This causes the warm air from the sea ice to be pushed above the boundary layer. Now two inversion layers are located above the observation site; a situation already described above (see Figure 11). Air from the sea ice moves southward in the altitude range between both inversion layers. The coincident increase in $\mathrm{BrO} \mathrm{dSCD}$ indicates that these air masses contain reactive bromine. (III) The original boundary layer retreats southward. Coincident with air from sea ice reaching the surface at the observation site, surface ozone depletion is observed.

[51] Satellite maps of the $\mathrm{BrO}$ vertical column density over Antarctica from the GOME satellite instrument shown in Figure 13 are in good agreement with the ground-based $\mathrm{BrO}$ measurements at Neumayer. Huge "clouds" of enhanced $\mathrm{BrO}$, covering areas of more than $5 \times 10^{6} \mathrm{~km}^{2}$ are present over the sea ice around the Antarctic continent. The bulk of the tropospheric $\mathrm{BrO}$ is typically located over the Weddell and Ross sea. The GOME observations of enhanced $\mathrm{BrO}$ close to the Antarctic coastline near Neumayer station agree well with periods of ozone depletion and $\mathrm{BrO}$ enhancement at Neumayer shown in Figures 7 and 8. The area of enhanced $\mathrm{BrO}$ around the Antarctic continent during spring 2000 is similar to the observations of 1999 . However, less frequent $\mathrm{BrO}$ enhancements were observed at Neumayer in 2000. This illustrates that the occurrence of local $\mathrm{BrO}$ enhancements and surface ozone depletion events at Neumayer during spring is mainly determined by the general meteorological conditions which control the origin of the probed air masses and determine if bromine-activated air masses located over the sea ice are transported to Neumayer station.

\section{Conclusions and Outlook}

[52] We presented some detailed case studies for the numerous $\mathrm{BrO}$ enhancements and surface ozone depletion events in the Antarctic coastal region which occurred during Austral spring of 1999 and 2000. They offered the possibility to study the dynamical and chemical aspects of the polar bromine explosion phenomenon in detail.

[53] We find that the majority of air masses originated from the sea ice contain reactive bromine. Some rare exceptions are most likely caused by mixing processes and/or uncertainties in the trajectory model. This surprisingly good agreement between the $\mathrm{BrO}$ measurements and the results from trajectory calculations in combination with sea ice maps confirms the theory that reactive bromine is released from sea-salt surfaces, which are provided either by sea ice surfaces and/or by uptake of sea-salt aerosols.

[54] Air masses at ground originating from sea ice surfaces, accompanied by $\mathrm{BrO}$ enhancements, are found to be a necessary prerequisite for surface ozone destruction. However, no reduction in surface ozone mixing ratio is observed in some cases, although the $\mathrm{BrO} \mathrm{dSCD}$ is strongly enhanced and the trajectory calculations suggest that the probed air masses were in contact with sea ice for several days. Our trajectory calculations suggest that these events can be attributed to $\mathrm{BrO}$ layers elevated from the surface.

[55] The trajectory calculations indicate that air masses from the sea ice are transported to altitudes of more than 

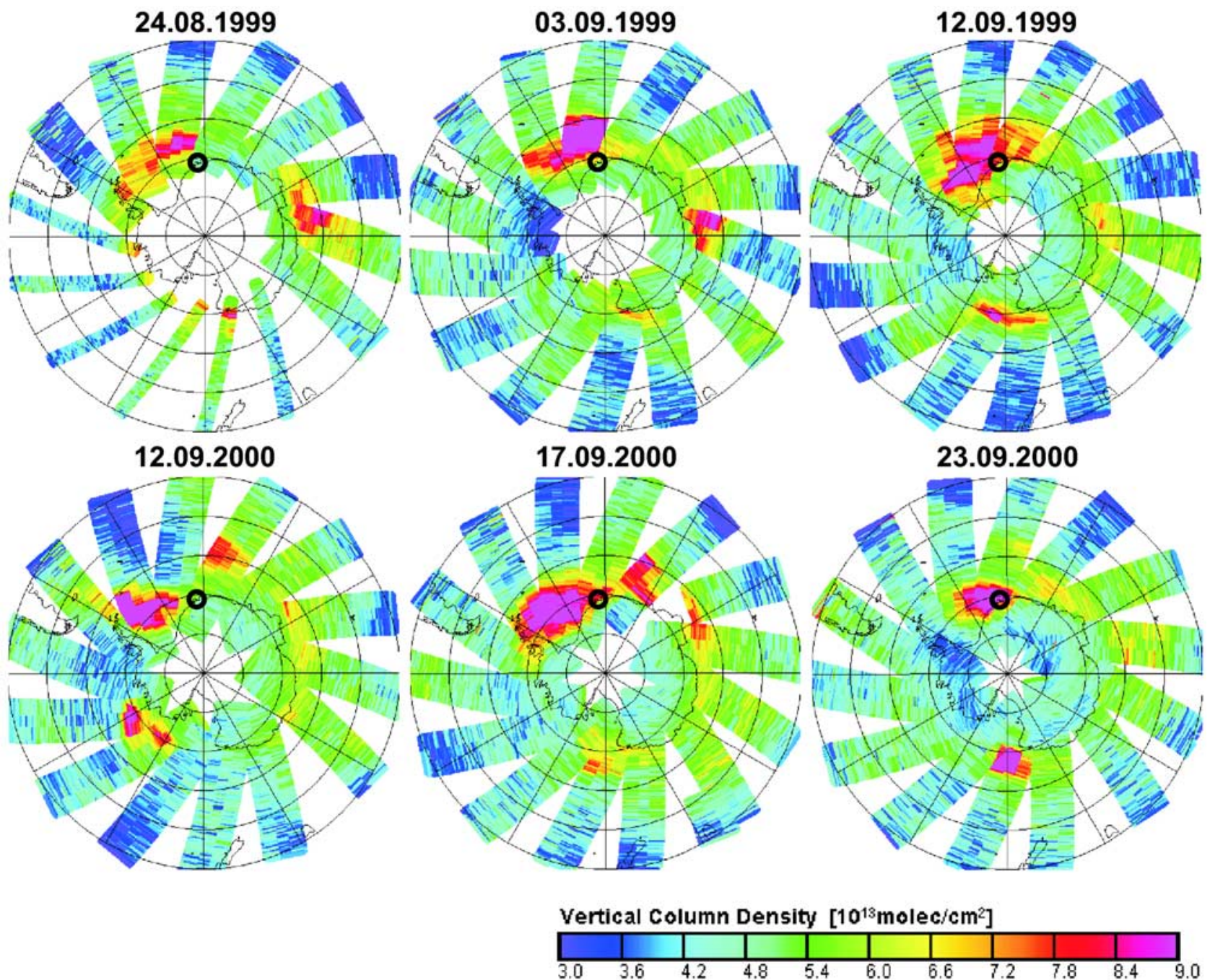

Figure 13. GOME maps of BrO VCD above Antarctica for some selected days in spring 1999 and 2000. The position of Neumayer station is marked by a circle.

$4000 \mathrm{~m}$ by advection processes, which are caused by cyclonic activity above the ice covered ocean. A possible consequence of these advection processes could be an input of reactive bromine into the free troposphere, as it was already observed in the Arctic by airborne spectroscopic measurements [McElroy et al., 1999]. These measurements over the Arctic sea ice suggest that $\mathrm{BrO}$ from the surface is transported into the free troposphere by convective processes. The analysis of trajectory calculations performed for the observations at Neumayer strongly suggests that the above described advection processes rather than convection are responsible for the transport of reactive bromine from the surface of the Antarctic shelf ice into the free troposphere. These processes would add large amounts of $\mathrm{BrO}$ to a possible background in the free troposphere, particularly since it can be expected that this uplift of bromine enriched air is not only restricted to the coastline around Neumayer but is widespread and frequently occurring during Antarctic spring. In contrast to stratospheric ozone (where absorption of UV radiation is the dominant effect), tropospheric ozone acts as a greenhouse gas owing to its absorption bands in the thermal infrared. As already pointed out elsewhere [Roscoe et al., 2001], the transport of reactive bromine into the free troposphere may have an impact on the ozone budget of the Antarctic free troposphere and therefore on the local climate in Antarctic spring.

[56] In most cases the observation of air masses originating from the sea ice is accompanied by a strong tropospheric light path enhancement, which amplifies the observed $\mathrm{BrO}$ dSCD owing to multiple scattering. Besides snow drift that could provide scattering particles, it is very likely that the light path enhancements are at least partially caused by seasalt aerosols which are transported from the sea ice surface to Neumayer station. Therefore it is possible that heterogeneous bromine release (or at least bromine "recycling") on the aerosol surfaces is still in progress at the observation site.

[57] Using measurements of the $\mathrm{O}_{4} \mathrm{dSCD}$ under snow drift conditions allows us to determine the path length through a strongly scattering layer. This information can be used to determine the near-surface $\mathrm{BrO}$ concentration, a topic that will be discussed in a forthcoming paper. 
[58] Since January 2003, the DOAS instrument at Neumayer has been equipped with a new multiaxis telescope. It allows us to observe scattered light from any elevation angle between zenith and horizon. Since the sensitivity for tropospheric trace gases increases when looking closer to the horizon, these measurements will allow us to separate tropospheric from stratospheric column and will yield information on the vertical distribution of tropospheric $\mathrm{BrO}$.

[59] Acknowledgments. Many thanks to the overwintering teams at Neumayer, especially Andrea Wille and Astrid Löwe, for operating and maintaining the DOAS instrument. The spectral retrieval was performed using the WINDOAS analysis software, developed by Caroline Fayt and Michel van Roozendael (Belgian Institute for Space Aeronomy, Brussels). The HYSPLIT trajectory model, the NCEP sea ice maps, and the FNL meteorological data were provided by the National Oceanic and Atmospheric Administration (NOAA).

\section{References}

Aliwell, S. R., et al. (2002), Analysis for BrO in zenith-sky spectra: An intercomparison exercise for analysis improvement, J. Geophys. Res., 107(D14), 4199, doi:10.1029/2001JD000329.

Chance, K., and R. J. D. Spurr (1997), Ring effect studies: Rayleigh scattering, including molecular parameters for rotational Raman scattering and the Fraunhofer spectrum, Appl. Opt., 36, 5224-5230.

Derber, J. C., D. F. Parrish, and S. J. Lord (1991), The new global operational analysis system at the National Meteorological Center, Weather Forecast., 6, 538-547.

Draxler, R. R. (1999), HYSPLIT 4 user's guide, NOAA Tech. Memo. ERL $A R L-230$, NOAA Air Resour. Lab., Silver Spring, Md.

Draxler, R. R., and G. D. Hess (1997), Description of the HYSPLIT 4 modeling system, NOAA Tech. Memo. ERL ARL-224, NOAA Air Resour. Lab., Silver Spring, Md.

Evans, M. J., et al. (2003), Coupled evolution of $\mathrm{BrO}_{x}-\mathrm{ClO}_{x}-\mathrm{HO}_{x}, \mathrm{NO}$ chemistry during bromine-catalyzed ozone depletion events in the arctic boundary layer, J. Geophys. Res., 108(D4), 8368, doi:10.1029/ 2002JD002732.

Fan, S. M., and D. J. Jacob (1992), Surface ozone depletion in the Arctic spring sustained by bromine reactions on aerosols, Nature, 359, 522-524.

Ferlemann, F., N. Bauer, H. Harder, H. Osterkamp, D. Perner, U. Platt, M. Schneider, P. Vradelis, and K. Pfeilsticker (2000), A new DOAS instrument for stratospheric balloon-borne trace gas studies, Appl. Opt., $39,2377-2386$

Fickert, S., J. W. Adams, and J. N. Crowley (1999), Activation of $\mathrm{Br}_{2}$ and $\mathrm{BrCl}$ via uptake of $\mathrm{HOBr}$ onto aqueous salt solutions, J. Geophys. Res., $104,23,719-23,727$

Frieß, U., T. Wagner, I. Pundt, K. Pfeilsticker, and U. Platt (2001), Spectroscopic measurements of tropospheric iodine oxide at Neumayer station, Antarctica, Geophys. Res. Lett., 28, 1941-1944.

Gäbler, H. E., and K. G. Heumann (1993), Determination of particulate iodine in aerosols from different regions by size fractionating impactor sampling and IDMS, Int. J. Environ. Anal. Chem., 50, 129-146.

Goodberlet, M., and C. T. Swift (1992), DMSP SSM/I sensor description and calibration, in NASA sea Ice Validation Program for the Defense Meteorological Satellite Program Special Sensor Microwave Imager, Final Report, NASA Tech. Memo. 104559, NOAA Air Resour. Lab., Silver Spring, Md.

Grainger, J. F., and J. Ring (1962), Anomalous Fraunhofer line profiles, Nature, 193, 762

Greenblatt, G. D., J. J. Orlando, J. B. Burkholder, and A. R. Ravishankara (1990), Absorption measurements of oxygen between 330 and $1140 \mathrm{~nm}$, J. Geophys. Res., 95, 18,577-18,582.

Hausmann, M., and U. Platt (1994), Spectroscopic measurements of bromine oxide and ozone in the high Arctic during Polar Sunrise Experiment 1992, J. Geophys. Res., 99, 25,399-25,414.

Hebestreit, K., J. Stutz, D. Rosen, V. Matveev, M. Peleg, M. Luria, and U. Platt (1999), First DOAS measurements of tropospheric BrO in midlatitudes, Science, 283, 55-57.

Hegels, E., P. J. Crutzen, T. Klüpfel, D. Perner, and J. P. Burrows (1998), Global distribution of atmospheric bromine monoxide from GOME on Earth-observing satellite ERS 2, Geophys. Res. Lett., 25, $3127-3130$

Hönninger, G., and U. Platt (2001), Observations of $\mathrm{BrO}$ and its vertical distribution during surface ozone depletion at Alert, Atmos. Environ., 36, $2481-2489$.
Kahl, J. D., J. M. Harris, and G. A. Herbert (1989), Intercomparison of three long-range trajectory models applied to Arctic haze, Tellus Ser. B, $41,524-536$.

Kanamitsu, M. (1989), Description of the NMC global data assimilation and forecast system, Weather Forecast., 4, 335-342.

König-Langlo, G., J. C. King, and P. Pettré (1998), Climatology of the three coastal Antarctic stations Durmont d'Urville, Neumayer, and Halley, J. Geophys. Res., 103, 10,935-10,946.

Kottmeier, C., and B. Fay (1998), Trajectories in the Antarctic lower troposphere, J. Geophys. Res., 103, 10,947-10,959.

Kreher, K., P. V. Johnston, S. W. Wood, and U. Platt (1997), Ground-based measurements of tropospheric and stratospheric $\mathrm{BrO}$ at Arrival Heights (78 ${ }^{\circ}$ S), Antarctica, Geophys. Res. Lett., 24, 3021-3024.

Kromminga, H., J. Orphal, P. Spietz, S. Voigt, and J. P. Burrows (2003), The temperature dependence (213-293 K) of the absorption cross-sections of OClO in the $340-450 \mathrm{~nm}$ region measured by Fourier-transform spectroscopy, J. Photochem. Photobiol., A, 157, 149-160.

Langendörfer, U., E. Lehrer, D. Wagenbach, and U. Platt (1990), Observation of filterable bromine variabilities during Arctic tropospheric ozone depletion events in high (1 hour) time resolution, Tellus, 34, $39-54$.

Lehrer, E. (1999), Polar tropospheric ozone loss, Ph.D. thesis, Univ. of Heidelberg, Heidelberg, Germany.

Levenberg, K. (1944), A method for the solution of certain non-linear problems in least squares, Q. Appl. Math., 2, 164-168.

Marquard, L. C., T. Wagner, and U. Platt (2000), Improved air mass factor concepts for scattered radiation differential optical absorption spectroscopy of atmospheric species, J. Geophys. Res., 105, 13151327.

Marquardt, D. W. (1963), An algorithm for least-squares estimation of nonlinear parameters, J. Soc. Indust. Math., 11, 431-441.

McElroy, C. T., C. A. McLinden, and J. McConnell (1999), Evidence for bromine monoxide in the free troposphere during the Arctic polar sunrise experiment, Nature, 397, 338-341.

Parrish, D. F., and J. C. Derber (1992), The National Meteorological Center's spectral statistical interpolation analysis system, Mon. Weather Rev., $120,1747-1766$

Platt, U. (1994), Differential optical absorption spectroscopy (DOAS), in Air Monitoring by Spectroscopic Techniques, vol. 127, pp. 27-84, John Wiley, Hoboken, N. J.

Platt, U., and E. Lehrer (1997), Arctic tropospheric ozone chemistry (ARCTOC), ARCTOC Final Rep., Eur. Union, Brussels.

Press, W. H., B. P. Flannery, S. A. Teukolsky, and W. T. Vetterling (1988), Numerical Recipes in C, Cambridge Univ. Press, New York.

Rankin, A. M., E. W. Wolff, and S. Martin (2002), Frost flowers - implications for tropospheric chemistry and ice core interpretation, J. Geophys. Res., 107(D23), 4683, doi:10.1029/2002JD002492.

Richter, A., F. Wittrock, M. Eisinger, and J. P. Burrows (1998), GOME observations of tropospheric $\mathrm{BrO}$ in northern hemispheric spring and summer 1997, Geophys. Res. Lett., 25, 2683-2686.

Ridley, B. A., et al. (2003), Ozone depletion events observed in the high latitude surface layer during the TOPSE aircraft program, J. Geophys. Res., 108(D4), 8356, doi:10.1029/2001JD001507.

Roscoe, H. K., K. Kreher, and U. Friess (2001), Ozone loss episodes in the free Antarctic troposphere, suggesting a possible climate feedback, Geophys. Res. Lett., 28, 2911-2914.

Solomon, S., A. L. Schmeltekopf, and R. W. Sanders (1987), On the interpretation of zenith sky absorption measurements, J. Geophys. Res., 92, $8311-8319$.

Stunder, B. J. B. (1997), NCEP model output-FNL archive data, NOAA Tech. Memo. TD-6141, Natl. Clim. Data Cent., Silver Spring, Md.

Stutz, J., and U. Platt (1996), Numerical analysis and estimation of the statistical error of differential optical absorption spectroscopy measurements with least-squares methods, Appl. Opt., 35, 6041-6051.

Tang, T., and J. C. McConnel (1996), Autocatalytic release of bromine from Arctic snow pack during polar sunrise, Geophys. Res. Lett., 23, 26332636.

Tuckermann, M., R. Ackermann, C. Gölz, H. Lorenzen-Schmidt, T. Senne, J. Stutz, B. Trost, W. Unold, and U. Platt (1997), DOAS-observation of halogen radical-catalysed Arctic boundary layer ozone destruction during the ARCTOC campaign 1995 and 1996 in Ny-Alesund, Spitsbergen, Tellus Ser. B, 49, 533-555.

Van Roozendael, M., M. de Maiziere, and P. C. Simon (1994), Ground based visible measurements at the Jungfraujoch Station since 1990, J. Quant. Spectrosc. Radiat. Transfer, 52, 231-240.

Vogt, R., P. J. Crutzen, and R. Sander (1996), A mechanism for halogen release from sea-salt aerosol in the remote marine boundary layer, Nature, 383, 327-330.

Voigt, S., J. Orphal, and J. P. Burrows (1999), UV-visible absorption crosssections of $\mathrm{NO}_{2}$ and $\mathrm{O}_{3}$ at atmospheric temperatures and pressures by 
FTS, in Proceedings of the 1st European Symposium on Atmospheric Measurements from Space (ESAMS-99), ESA WPP-161, vol. 2, pp. 443-465, Eur. Space Ag., ESTEC, Noordwijk, Netherlands.

Wagner, T., and U. Platt (1998), Observation of tropospheric BrO from GOME satellite, Nature, 395, 486-490.

Wagner, T., C. Leue, M. Wenig, K. Pfeilsticker, and U. Platt (2001), Spatial and temporal distribution of enhanced boundary layer $\mathrm{BrO}$ concentrations measured by the GOME instrument aboard ERS-2, J. Geophys. Res., 106, $24,225-24,236$

Wagner, T., C. von Friedeburg, M. Wenig, C. Otten, and U. Platt (2002), UVvisible observations of atmospheric $\mathrm{O}_{4}$ absorptions using direct moonlight and zenith-scattered sunlight for clear-sky and cloudy sky conditions, J. Geophys. Res., 107(D20), 4424, doi:10.1029/2001JD001026.
Wilmouth, D. M., T. F. Hanisco, N. M. Donahue, and J. G. Anderson (1999), Fourier transform ultraviolet spectroscopy of the $A^{2} \Pi_{3 / 2} \leftarrow$ $X^{2} \Pi_{3 / 2}$ transition of BrO, J. Phys. Chem., 103, 8935-8945.

U. Frieß, Space Research Centre, University of Leicester, Leicester LEI 7RH, UK. (uf5@le.ac.uk)

J. Hollwedel, T. Wagner, and U. Platt, Institut für Umweltphysik, Im Neuenheimer Feld 229, D-69120 Heidelberg, Germany.

G. König-Langlo, Alfred Wegener Institut für Polar- und Meeresforschung, Columbusstraße, D-27568 Bremerhaven, Germany. (uf5@1e.ac. uk) 